Portland State University

PDXScholar

2-18-1983

\title{
Breeding Success and Nest Site Characteristics of the Western Bluebird on Parrett Mountain
}

Marcia Diane Sims

Portland State University

Follow this and additional works at: https://pdxscholar.library.pdx.edu/open_access_etds

Part of the Biology Commons, and the Ornithology Commons Let us know how access to this document benefits you.

\section{Recommended Citation}

Sims, Marcia Diane, "Breeding Success and Nest Site Characteristics of the Western Bluebird on Parrett Mountain" (1983). Dissertations and Theses. Paper 3395.

https://doi.org/10.15760/etd.5281

This Thesis is brought to you for free and open access. It has been accepted for inclusion in Dissertations and Theses by an authorized administrator of PDXScholar. Please contact us if we can make this document more accessible: pdxscholar@pdx.edu. 
AN ABSTRACT OF THE THESIS OF Marcia Diane Sims for the Master of Science in Biology presented February 18, 1983.

Title: Breeding Success and Nest Site Characteristics of the Western Bluebird on Parrett Mountain.

APPROVED BY MEMBERS OF THE THESIS COMMITTEE:

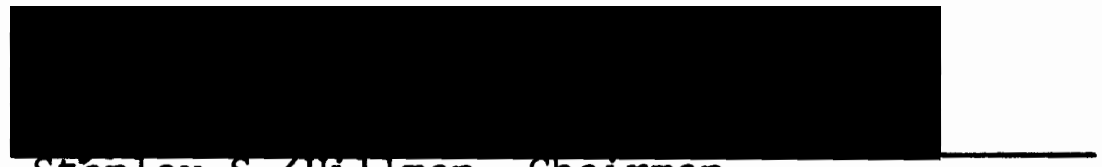

stanley S.jHillman, Chairman
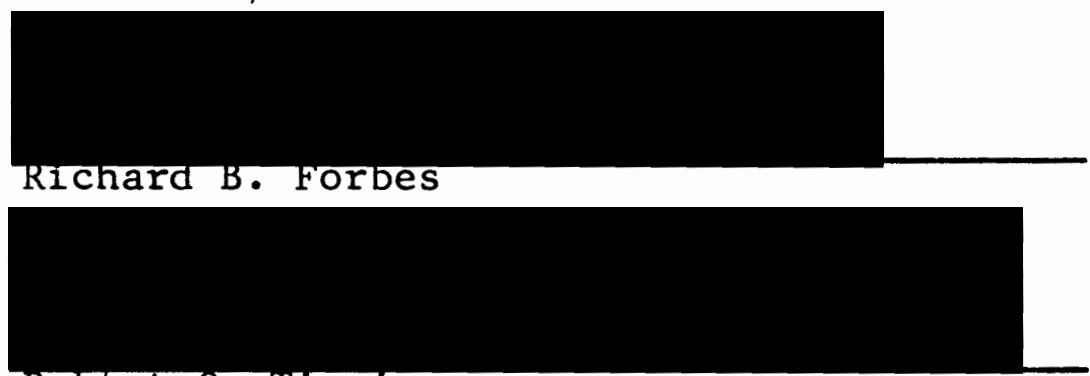

Robert 0. Tinnin

The lack of suitable nest sites may be a limiting

factor for Western Bluebird populations inhabiting the upper Willamette Valley. Nest box trails have been established on the hills surrounding the Portland metropolitan area. Since their placement, approximately $25 \%$ of the boxes available have been used by Western Bluebirds as nest cavities. This study was undertaken to identify factors which might determine the selection of a nest box by Western Bluebirds and the subsequent nest success or failure.

The breeding biology of Western Bluebirds using the 
nest box trail located on Parrett Mountain, Oregon in 1979 was investigated. Breeding season, mean clutch size, average incubation and nestling periods, and level of nest success were determined.

Nest box dimensions, placement, and surrounding habitat features were quantified. Potentially important nest site characteristics were examined and tested for association with Western Bluebird nest box use and reproductive success. Western Bluebird nest box selection was random with regard to all of the characteristics studied except Solar Index and Nest Box Density. No correlation was seen between nest box characteristics and bluebird nest success . 


\title{
BREEDING SUCCESS AND NEST SITE CHARACTERISTICS OF THE WESTERN BLUEBIRD ON PARRETT MOUNTAIN
}

\author{
by \\ MARCIA DIANE SIMS
}

A thesis submitted in partial fulfillment of the requirements for the degree of

\author{
MASTER OF SCIENCE \\ in \\ BIOLOGY
}

Portland State University

1983 
TO THE OFFICE OF GRADUATE STUDIES AND RESEARCH:

The members of the Committee approve the thesis of Marcia Diane Sims presented February 18, 1983.

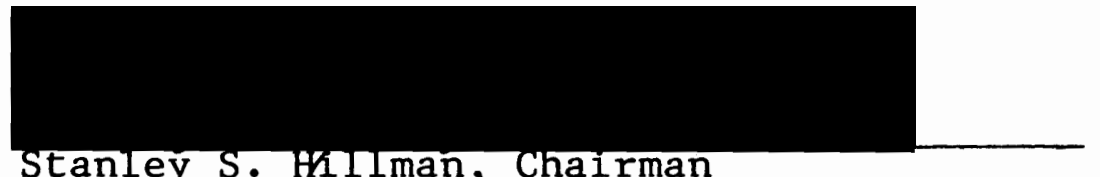
Stanley s. Hillman, Chairman

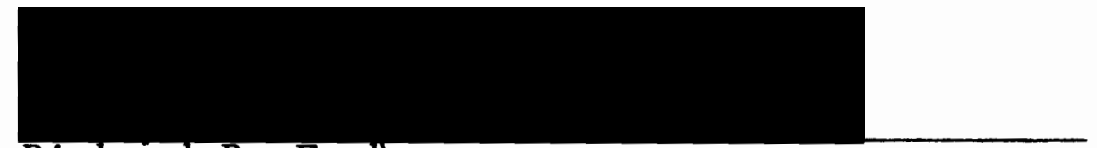
Richard B. Forbes

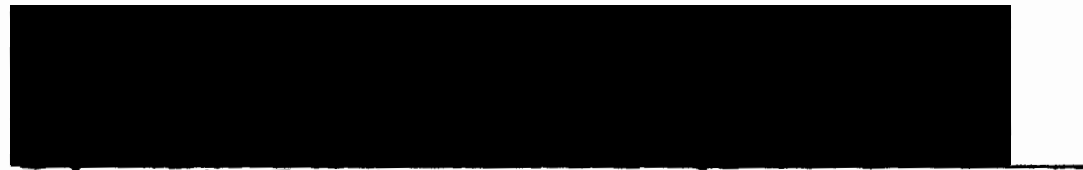

Robert 0. Tinnin

APPROVED :

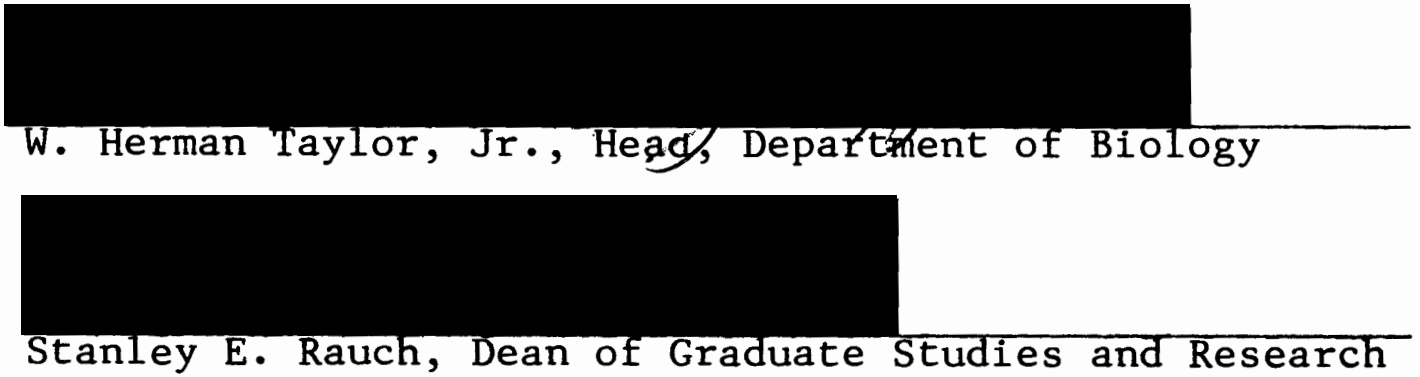




\section{ACKNOWLEDGMENTS}

Sincere appreciation is given to Dr. Stanley S. Hillman for his comments and criticisms during the course of my research and in the preparation of this thesis, and for his ongoing enthusiasm. Appreciation is also extended to Dr. Richard B. Forbes, Dr. Robert O. Tinnin, and Dr. Earl R. Rosenwinkel for their advice and use of laboratory space and equipment.

I would specifically like to acknowledge Mr. Hubert W. Prescott, who was instrumental in establishing the Parrett Mountain nest box trail, and who gave generously of his time and ideas regarding Western Bluebird breeding biology and nest box competition.

Thanks are given to Cliff Perry and Lynn Larsen for their field assistance, to the Portland Audubon Society nest box trail managers, and the landowners on Parrett Mountain. Finally, I would like to thank my husband, Bruce W. Richey, for the illustrations and graphs, and for his continuing support and encouragement. 
TABLE OF CONTENTS

PAGE

ACKNOWLEDGMENTS . . . . . . . . . . . . . . . . iii

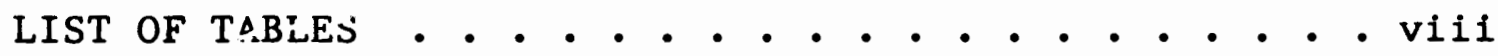

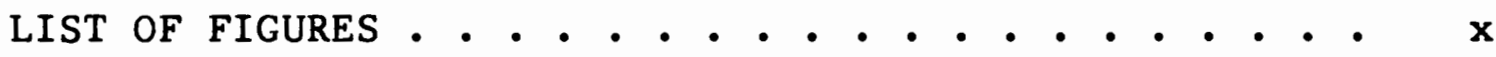

INTRODUCTION . . . . . . . . . . . . . . . . 1 LITERATURE REVIEW

WESTERN BLUEBIRD NATURAL HISTORY • • • • • • 3

Distribution In Oregon . . . . . . . . 3

Population Numbers . . . . . . . . 3

Habitat . . . . . . . . . . 5

Nest Location . . . . . . . . . 6

Nest Site Competition . . . . . . . 7

Nest Design . . . . . . . . . 8

Food . . . . . . . . . . . . 8

Foraging Strategies . . . . . . . . 9

Predation . . . . . . . . . . 10

Breeding Biology . . . . . . . . 10

STUDY AREA . . . . . . . . . . . . . . . 13

WESTERN BLUEBIRD BREEDING BIOLOGY

INTRODUCTION • . . . . . . . . . . . 21

MATERIALS AND METHODS ............. 21

Statistics . . . . . . . . . 22 
PAGE

Breeding Season . . . . . . . . 22

Clutch Size............. 22

Incubation And Nestling Periods . . . . 24

Nest Success . . . . . . . . . 25

Mortality ............ 25

Parasitism ............ . 26

Nest Box Competition . . . . . . . 26

RESULTS . . . . . . . . . . . . . 26

Breeding Season .......... . 26

Clutch Size... . . . . . . . 29

Incubation And Nestling Periods . . . . . 31

Nest Success . . . . . . . . . 31

Mortality . . . . . . . . . 34

Parasitism . . . . . . . . . 37

Nest Box Competition . . . . . . . 37

DISCUSSION • • . . . . . . . . . 38

Breeding Season . . . . . . . 38

Time of Laying, Egg Color, And Clutch Size 39

Incubation And Nestling Periods . . . . 40

Nest Success . . . . . . . . . 42

Mortality .. . . . . . . . . 44

Parasitism ............ . 45

Nest Box Competition . . . . . . . 46

WESTERN BLUEBIRD NEST SITE CHARACTERISTICS

INTRODUCTION . . . . . . . . . . . 49 
PAGE

MATERIALS AND METHODS . • . . . . . . . 50

Nest Box Location . . . . . . . 51

Nest Box Design . . . . . . . . 51

Nest Box Placement . . . . . . . 52

Entrance Orientation . . . . . . . 52

Solar Index . . . . . . . . . . 52

Nest Box Density Index . . . . . . . 53

Nest Site Characteristics And Mortality . • 53

Nest Box Temperatures . . . . . . . 54

RESULTS . . . . . . . . . . . . . 55

Nest Box Location . . . . . . . 55

Nest Box Design . . . . . . . . 55

Nest Box Placement . . . . . . . 58

Entrance Orientation . . . . . . . 58

Solar Index . . . . . . . . . 62

Nest Box Density Index . . . . . . . 62

Nest Site Characteristics And Mortality • 63

Nest Box Temperatures . . . . . . 63

DISCUSSION . . . . . . . . . 67

Entrance Orientation ......... 67

Solar Index . . . . . . . . . . 72

Nest Box Density Index . . . . . . 73

Nest Site Characteristics And Mortality • $\quad 73$

Nest Box Temperatures. . . . . . . 74 
vii

PAGE

APPENDIX A - WESTERN BLUEBIRD NEST RECORD CARD ANALYSIS 79 APPENDIX B - DETERMINING MAYFIELD'S NEST SUCCESS • • 84 LITERATURE CITED . . . . . . . . . . . . . 90 


\section{LIST OF TABLES}

TABLE

PAGE

I Seasonal Variation in Western Bluebird Clutch

Size on Parrett Mountain, 1979 . . . . . 30

II Western Bluebird Nest Development and Breeding

Success on Parrett Mountain, 1979 . . . . 32

III Clutch Size and Nest Productivity for Western

Bluebirds Breeding on Parrett Mountain,

1979 . . . . . . . . . . . .

IV Western Bluebird Breeding Success and Sources

of Mortality on Parrett Mountain, 1979 • 35

$V$ Timing of Western Bluebird Nest Failures on

Parrett Mountain, 1979 . . . . . . 36

VI Western Bluebird Breeding Biology Data from

Nest Box Studies . . . . . . . . 41

VII Nest Box Location and Western Bluebird Use on

Parrett Mountain, 1979 . . . . . . 56

VIII Nest Box Design and Western Bluebird Use on

Parrett Mountain, 1979 . . . . . . 57

IX Nest Box Placement and Western Bluebird Use on Parrett Mountain, 1979 ....... 59

$\mathrm{X}$ Comparison of Mean Nest Site Characteristics

for Individual and Whole-rest Sources of 
Mortality for Western Bluebirds on Parrett Mountain, 1979 . . . . . . . 64

XI Western Bluebird Individual and Whole-nest Mortality Related to Nest Box Location on Parrett Mountain, 1979 . . . . . . 65

XII Entrance Orientation, Solar Index, and Mean Nest Box Temperature Change for Parrett Mountain, 1979 . . . . . . . . . 66

XIII Mayfield's Success of Nests and Eggs/Nestlings According to the Stage of the Nesting Cycle for Western Bluebirds on Parrett Mountain, 1979 . . . . . . . . . 


\section{LIST OF FIGURES}

FIGURE

PAGE

1. Parrett Mountain Study Area, 1979 . . . . . 14

2. Plans for a Side-opening Bluebird Nest Box . . 19

3. A Nest Box Record Card . . . . . . . . 23

4. Western Bluebird Nesting Calendar for Parrett Mountain, 1979 . . . . . . . . . . 27

5. Compass Orientation of Nest Box Entrance Holes on Parrett Mountain, 1979 . . . . . .

6. Compass Orientation and Timing of Western

Bluebird Nest Attempts on Parrett Mountain, 1979 . . . . . . . . . . .

7. Variation in Maximum Ambient and Nest Box

Temperatures at Site 1 on Parrett Mountain,

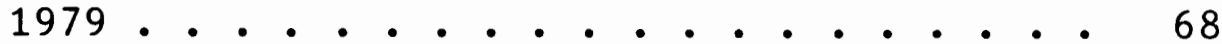

8. Influence of Orientation on Maximum Nest Box

Temperatures at Site 2 on Parrett Mountain, 1979 • . . . . . . . . . . . .

9. Influence of Shading on Maximum Nest Box

Temperatures at Site 3 on Parrett Mountain, 1979 . . . . . . . . . . . . 70 
10. Influence of Orientation on Maximum Nest Box

Temperatures at Site 3 on Parrett Mountain, 1979 • • • . • • . • • . . . . . . 


\section{INTRODUCTION}

There is increasing concern that the Western Bluebird (Sialia mexicana Townsend) has been declining in numbers over its range for several decades (Zeleny 1973). The Western Bluebird is a secondary (non-excavating) cavity nesting species. Competition for nest sites occurs among cavity nesting bird species (von Haartman 1957). The scarcity of cavities for nests or roosting may be a factor limiting the populations and diversity of cavity nesters (Beebe 1974, cited in Gary and Morris 1980).

The introduction to the United States of the House Sparrow (Passer domesticus) and Starling (Sturnus vulgaris) may be partially responsible for lowered population levels of the genus Sialia. House Sparrows and Starlings are aggressive species which use, but do not require, cavities for nest sites. Bluebirds seldom compete successfully with Starlings for the use of any cavity that the Starlings can enter. The smaller House Sparrow can readily enter any hole that bluebirds can, and will aggressively displace bluebirds from a disputed site. Starlings and House Sparrows will destroy bluebird eggs, young, and adults (Zeleny 1976). Modern land use practices have eliminated many naturally occurring cavities in trees that might have been used as nest sites. Thus the supply of 
natural cavities is being steadily reduced.

Bluebird nest box trails have been started throughout the United States to provide additional nest sites for bluebirds and other native species. These trails consist of large numbers of Starling-proof nest boxes placed in good habitat along roads, on farms, in parks, and on golf courses (McKnight 1973). Western Bluebird nest box trails have been established on many of the low hills surrounding the Portland metropolitan area. Prescott (1977) noted that Western Bluebirds were successfully using about $25 \%$ of the $450+$ boxes available to them on the Portland area trails. Prescott's finding raises several questions. If nest cavities are in short supply, what governs the selection and success of a given bluebird nest box? Do adult bluebirds choose nest boxes independently of specific nest site characteristics such as box orientation or height above ground, or does box selection show a correlation with nest site characteristics?

This study of the Western Bluebird on Parrett Mountain, Oregon, was based on the analysis of 80 nest card records obtained during the breeding season from April to September 1979. My purposes were to investigate Western Bluebird breeding biology, to identify and quantify potentially important nest site characteristics, and to examine the relationship between these characteristics and Western Bluebird breeding success. 


\section{LITERATURE REVIEW}

\section{WESTERN BLUEBIRD NATURAL HISTORY}

\section{Distribution In Oregon}

The Western Bluebird is a permanent resident in Oregon west of the Cascades and breeds throughout the state in the summer (Gabrielson and Jewett 1940). Small flocks of Western Bluebirds stay all year round in Oregon (Finley 1907). Early records include sitings at Fort Klamath (Merrill 1888), John Day (Miller 1904), in Baker County (Jewett 1909), in Tillamook County (Jewett 1916), at Clear Lake (Willett 1919), Wallowa Valley (Gabrielson 1924), and the Rogue River Valley (Gabrielson 1931). Walker (1917) listed Western Bluebirds as abundant in the open timber of central Oregon. Antony (1886) and Jewett and Gabrielson (1929) described Western Bluebirds as very common summer residents in the Portland area.

Population Numbers

Gabrielson and Jewett (1940) stated that the Western Bluebird ranked with the American Robin (Turdus migratorius) in abundance. Dramatic declines in Eastern Bluebird (Sialia sialis) population numbers during this century (Musselman 1934, Wallace 1959, James 1963, Atkinson 1974, Robbins 1974) have created concern that a similar 
downward trend might be occurring with Mountain (Sialia currucoides) and Western Bluebirds (Power 1966, Zeleny 1973). The genus Sialia was 1isted in American Birds (Anonymous 1971) as "substantially reduced in numbers, either regionally or throughout their range".

Western Bluebird numbers in Oregon's Willamette Valley have been falling since 1948 according to Christmas Bird Counts (Prescott 1977). Prescott (1979) reported the retreat of Western $B l u e b i z d s$ from the valley into the surrounding hilly terrain. Marshall (1978) stated that Western Bluebirds may have disappeared from the Willamette Valley entirely as a nesting species. The species is now classified as uncommon in Oregon except along the coast where it is regarded as rare (Bertrand and Scott 1979). Herlugson (1978) found that museum collections and published reports indicated a decline in the breeding populations of Western Bluebirds west of the Cascade Mountains in Washington. However, in an analysis of winter distribution and abundance patterns for the genus Sialia, Andrews and Block (1979) found Western Bluebird populations to be generally stable across their range for the period from 1962-1972.

Possible reasons for lowered Sialia populations include habitat destruction, changing farm practices, competition for nest sites, the use of insecticides, adverse weather, and reduced winter food supplies (Zeleny 1976). 
Prescott (1980) concluded that the move to modern farm practices which resulted in the destruction of prime bluebird habitat was the most significant cause of a Western Bluebird population decline in the Willamette Valley.

\section{$\underline{\text { Habitat }}$}

The Western Bluebird inhabits open, parklike land of scattered coniferous or hardwood trees. An edge species, it prefers the meeting of forest and field (Dice 1918, Pederson and Bryant 1975, Gary and Morris 1980) or clearings in the woods (Ray 1905, Burleigh 1921, 1930). Johnson (1965) reported that snags near open ground were favored nest sites. Swarth (1904), Miller (1951), Phillips et al (1964), Bailey and Niedrach (1965), and Herlugson (1978) found that the Western Bluebird was abundant in the open mountain pine forests (often Pinus ponderosa) of the Transition Zone. Richardson (1904) stated that Western Bluebirds were common everywhere in the California mountains, but most numerous among the pines and firs. Western Bluebirds were often seen in forested areas between 1,980-2,900 m (Lowe 1894, Jensen 1923, Ligon 1961). According to Cooke (1895) and Packard (1945), Western Bluebirds stayed below timberline in the ponderosa belt of Colorado. Western Bluebirds were also found in oak (Evermann 1886, Marshall 1957, Small 1974) and pinyon-juniper (Swarth 1924, Tatschl 1967) woodlands of California and Arizona.

The species appears to have taken advantage of 
urbanization in the West. Western Bluebirds invaded openings created by clearcut logging (Fisher 1902, Franzreb and Ohmart 1978), and nested near farm buildings and along the streets of towns (Jewett et al 1953). They even increased in numbers around cities early in this century (Rathburn 1902, Shepardson 1915).

Nest Location

During the breeding season, the prime habitat requirement for Western Bluebirds is well spaced, broken timber which provides nest sites and an abundance of perches (Grinnell and Miller 1944). Western Bluebirds prefer to nest in old woodpecker holes (Rockwell and Wetmore 1914, Dixon 1943, Troetschler 1976) or natural cavities in trees or snags (Antony 1886, Barlow 1901, Ray 1912). Their nests have been found in oak (Clabaugh 1924), pine (Ray 1905, 1914, Burleigh 1921), sycamore (Myers 1912), aspen (Packard 1945), willow (Goldman 1908), and cottonwood (Thompson 1900, Racey 1926, 1948) trees. Western Bluebirds have also used abandoned mud swallow nests (Merriam 1896, Abbott 1927) to raise their young. Other reported nest sites include a hole in a telephone pole (Johnston 1949), crevices in buildings (Arnold and Pemberton 1916, Ross 1933), a mailbox (Chambers 1915), a metal pipe (Árnold 1937), and bird houses (Bowles 1906, Finley 1907, Cowles 1933, Seibert 1942). 
Nest Site Competition

Often a tree contains the nests of several different cavity nesting species (Edwards 1914, Hering 1948). Western Bluebirds can compete with some bird species and small mamma1s for suitable nest sites. Ray (1918) observed Western Bluebirds and Mountain Chickadees (Parus gambeli) trying to build a nest in the same cavity. House Wrens (Troglodytes aedon) (Bent 1949), Nuttall's Woodpeckers (Picoides nuttallii) (Miller and Bock 1972), and Violet-green Swallows (Tachycineta thalassina) (Winternitz 1976) may compete aggressively with Western Bluebirds for natural cavities. Western Bluebirds have driven away squirrels, chipmunks, and Western Tanagers (Piranga 1udoviciana) that came too near their nests (Williams 1900, Hering 1948). Purple Martins (Progne subis) (Richmond 1953), Violet-green Swallows (Racey 1939), and Ash-throated Flycatchers (Myiarchus cinerascens) (Gandor 1960) have all been reported to fight with Western Bluebirds for bird boxes.

The Portland Audubon Society listed the following species as having used nest boxes on their Western Bluebird trails: House Sparrows, Tree Swallows (Iridoprocne bicolor), Violet-green Swallows, Starlings, Black-capped Chickadees (Parus atriacapillus), Chestnut-backed Chickadees (Parus rufescens), White-breasted Nuthatches (Sitta carolinensis), House Wrens, Bewick's Wrens 
(Thryomanes bewickii), Townsend chipmunks (Eutamias

townsendii), Douglas squirrels (Tamiasciurus douglasi), and deer mice (Peromyscus maniculatus).

Nest Design

Western Bluebird nests are loosely built in a cavity and are typically composed of dry grass or weeds (Burleigh 1921, Gandor 1960). Nests are 6-11 cm high with a deep cup. Although usually homogeneous in design, fine bark strips (Ray 1912, 1914), cottonwood fibers (Thompson 1900), or horse hair (Finley 1907) have been used as lining. Occasionally a feather is included. A Western Bluebird nest was found in a woodpecker hole $25 \mathrm{~cm}$ deep with an $8 \mathrm{~cm}$ diameter about $9 \mathrm{~m}$ up from the ground in a pine tree (Rockwell and Wetmore 1914). Clabaugh (1924) reported a nest $3 \mathrm{~m}$ up in an oak. The opening was $5 \mathrm{~cm}$ in diameter, and the cavity was $25 \mathrm{~cm}$ deep. In a study done by Hering (1948), 7 Western Bluebird nests were located in old pines at heights varying from 3 to $10 \mathrm{~m}$. Gary and Morris (1980) found that Western Bluebirds would use large nest boxes with $7.6 \mathrm{~cm}$ entrance holes located $6 \mathrm{~m}$ above ground when there were no other nest sites available.

Food

Systematic studies by Beal (1915) and Herlugson (1980) found that grasshoppers (Orthoptera), caterpillars (Lepidoptera), beetles (Coleoptera), and ants (Hymenoptera) 
composed the major portion of the Western Bluebird diet. Other accounts of insect consumption include observations by Grinnell (1905), Cowan (1942), Popper (1951), and Gander (1960). Vegetable material is commonly eaten during the winter months. Mistletoe berries (Phorandendron sp.) (Price 1899, Bryan 1901, Mailliard and Grinnell 1905, Grinnel1 1911, Michael 1936, Carter 1937, Jaeger 1949, Ingles 1950, Riney 1951, Roest 1957, Guillion et al 1959, Walsberg 1975) are a favorite food. Preferences for juniper berries (Junipersus sp.) (Townsend 1925, Ligon 1961, Phillips et al 1964, Salomonson and Balda 1977) and other fruits (Grinnell 1904, Beal 1915, Cowles 1933, Felters 1936, Stoner 1940, Davis 1957) have also been noted.

\section{Foraging Strategies}

Western Bluebirds typically sit on an exposed perch and search for insects. After a suitable prey is located on the ground, the bird drops, seizes the insect with its bill, and returns to a perch (Bryant 1911, Mansfield 1946). Herlugson (1980) concluded that dropping or perch foraging was the primary foraging tactic used by Western Bluebirds during the breeding season. Western Bluebirds have also been reported to use flycatching (Storer 1919, Bent 1949, Marshall 1957), hovering (Grinnell and Miller 1944, Ligon 1961), and soaring (Pitelka 1941) to obtain food. Eastern Bluebirds (Pinkowski 1977c) and Mountain Bluebirds (Power 1980) use similar methods. Foraging strategies are 
described in detail for the genus Sialia by Pinkowski $(1979 a)$.

Predation

Pinkowski (1975) and Zeleny (1976) cited raccoons (Procyon lotor), opossums (Didelphis marsupialis), House Wrens, House Sparrows, Starlings, house cats, squirrels, chipmunks, snakes, mice (Peromyscus sp.), and man as having been responsible for the destruction of bluebird eggs, nestlings, or fledgings. On the West Coast, the Pacific gopher snake (Pituophis melanoleucus) and the western yellow-bellied racer (Coluber constrictor) have been found in or near nest boxes (Dahlsten and Copper 1979, Prigge 1979). Weasels (Mustela sp.) (Criddle 1927, Erskine and McLaren 1972, Dahlsten and Copper 1979), and predatory birds (Drinkwater 1953, Mills 1976, Harris 1919) are also nest box predators.

Breeding Biology

In the Portland area, Western Bluebirds associate in winter flocks until late in January or February (Jewett and Gabrielson 1929), when they begin to establish territories and form pairs. Courtship activity centers around possible nest sites. Bluebirds use a type "A" territory (Nice 1941) where courtship, breeding, nesting, and food seeking occur. Balda (1975, cited in Pinkowski 1979a) determined a territory size for Western Bluebirds in ponderosa pine 
forests of 0.4 ha. Depending on weather conditions, nest-building may start in March or April. The female builds the nest. The duration of the nest-building stage and the interval between building and egg-laying are not documented. Eggs are smooth, glossy, light blue in color, and average $21 \times 16 \mathrm{~mm}$ in size. Clutch size is usually between 4 and 6 eggs, with extremes of 3 and 8 . Western Bluebirds are very persistent and may lay a second set of eggs within a short time if the first set is removed (Bent 1949). The laying of 1 egg per day is assumed. In a Portland survey by Griffee and Rapraeger (1937), 20 April was given as the earliest clutch completion date with 27-28 April being the height of the season for first broods. After an incubation period of 13-14 days, the young hatch and have tufts of bluish gray down on their head and back (Harrison 1978). They are brooded by the female, and their eyes open at 8-9 days (personal observation). Both adults feed the nestlings. Fledging usually takes place 20-22 days after hatching (E1zroth, Prescott, and Prigge personal communications). Western Bluebird juvenile and adult plumage and molting were studied in detail by Ridgeway (1894, 1907). Elzroth (1981) described an incomplete albino nestling found in a nest box near Corvallis, Oregon.

The male tends the young while the female renests. Western Bluebirds often raise 2 and sometimes 3 broods during a breeding season (Finley 1907, Gabrielson and Jewett 
1940). A second nest may be built on top of the used first brood nest. Young of the first brood have been observed to feed nestlings of the second brood (Finley 1907, Seibert 1942, Skutch 1961, personal observation). In the fall, the birds form small family flocks and roam the hills and mountains . 


\section{STUDY AREA}

The study area was located $24 \mathrm{~km}$ southwest of Portland and $6 \mathrm{~km}$ northeast of Newberg, Oregon on Parrett Mountain $\left(45^{\circ} 19^{\prime} \mathrm{N}, 122^{\circ} 50^{\prime} \mathrm{W}\right)$ in a hilly region of the upper Willamette Valley. It covered portions of Yamhill, Clackamas, and Washington counties. Elevations range from 60-335 m. Well drained clay loams are found on the low basalt hill (U.S.D.A. Soil Conservation Service 1974). Figure 1 is a general map of the study area. Insert maps A, $B$, and $C$ show the roads and nest box locations used for this project in 1979 .

Nest boxes of a standard bluebird box design (Figure 2 ) were initially placed on Parrett Mountain in 1973 (Prescott 1979). Boxes were added each year until over 90 were available in 1979. The nest box trail follows approximately $19 \mathrm{~km}$ of country roads which cross Parrett Mountain from north to south. It is part of a larger Portland area Western Bluebird trail developed by Prescott (1977) and now managed by the Portland Audubon Society.

The modified marine climate of the region is characterized by mild, wet winters with prolonged cloudy periods and cool, dry summers. Temperature extremes for 1970-1981 ranged from $-13^{\circ} \mathrm{C}$ in January to $39^{\circ} \mathrm{C}$ in July. The average daily temperature for January 1979 was $-0.3^{\circ} \mathrm{C}$ and 
Figure 1. Parrett Mountain study area, 1979. Insert maps $A, B$, and $C$ show the roads and nest box locations in the research area. Dots represent nest boxes already present. Open circles stand for nest boxes that were erected in 1979 for this project. The letters A-K mark the nest boxes which were part of the temperature studies done at 4 different sites: Site 1 = boxes A, B, C, D, E; Site 2 = boxes $F$ and $G$; Site 3 = boxes $H, I, J$; Site $4=$ box $K$. 


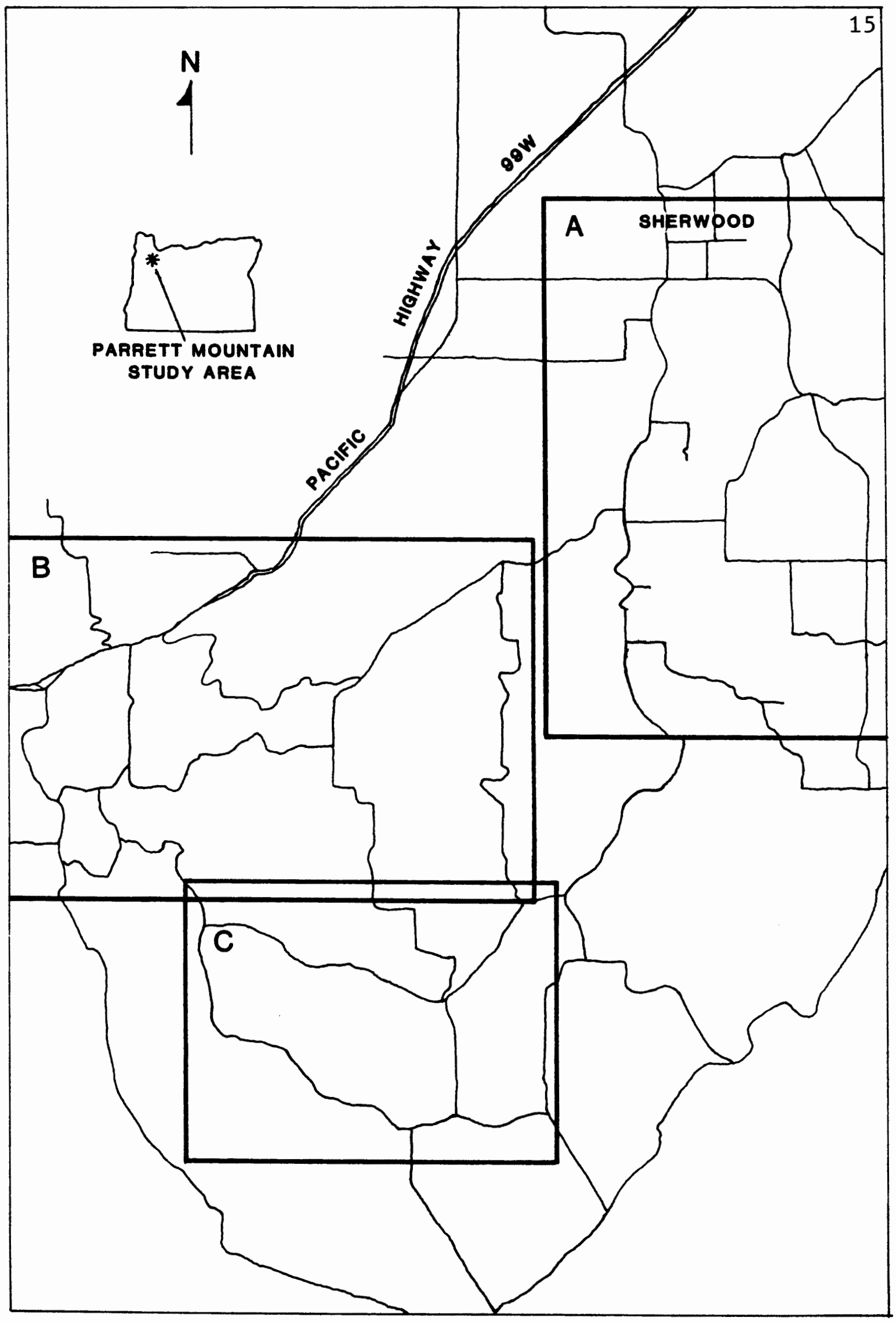




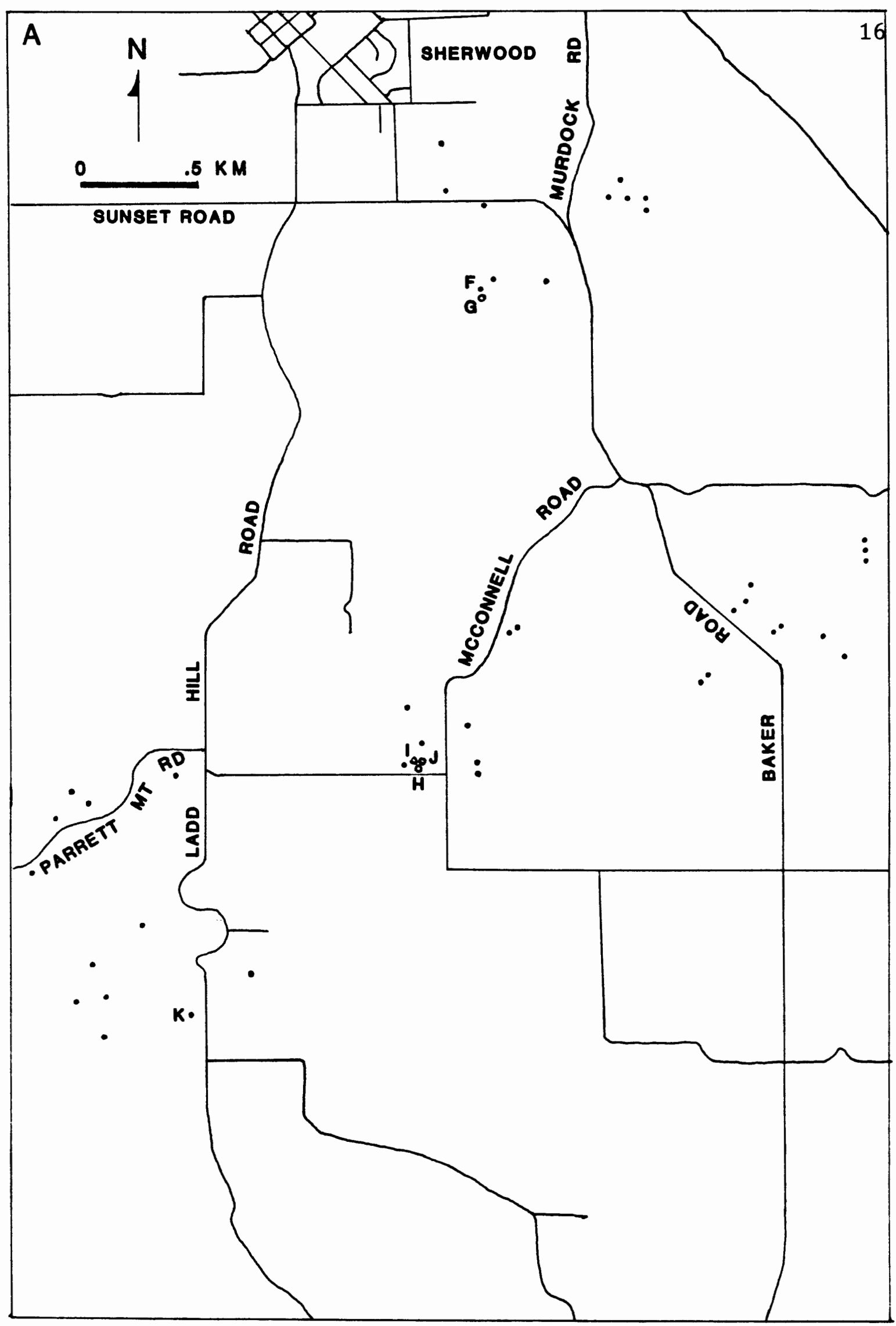




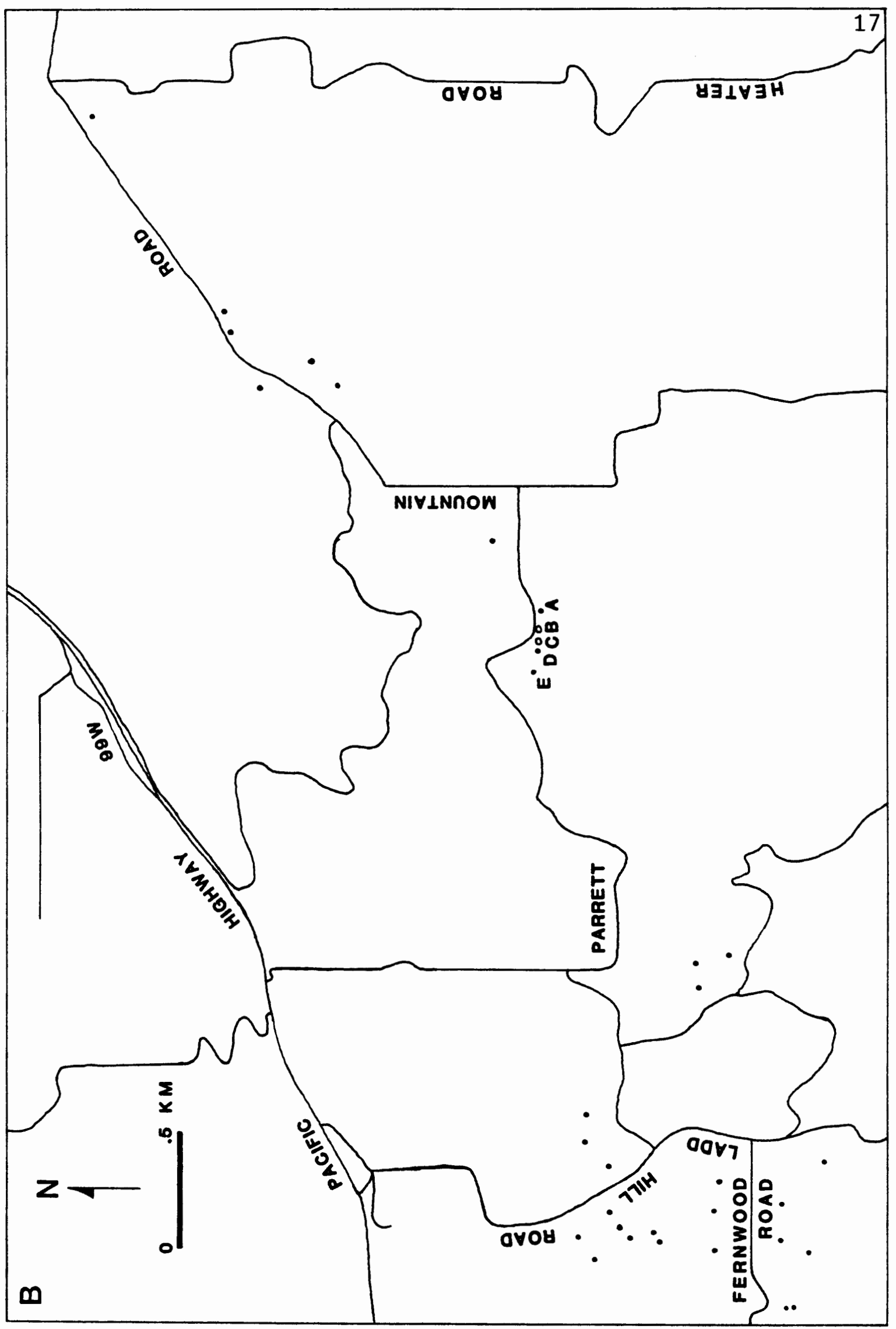




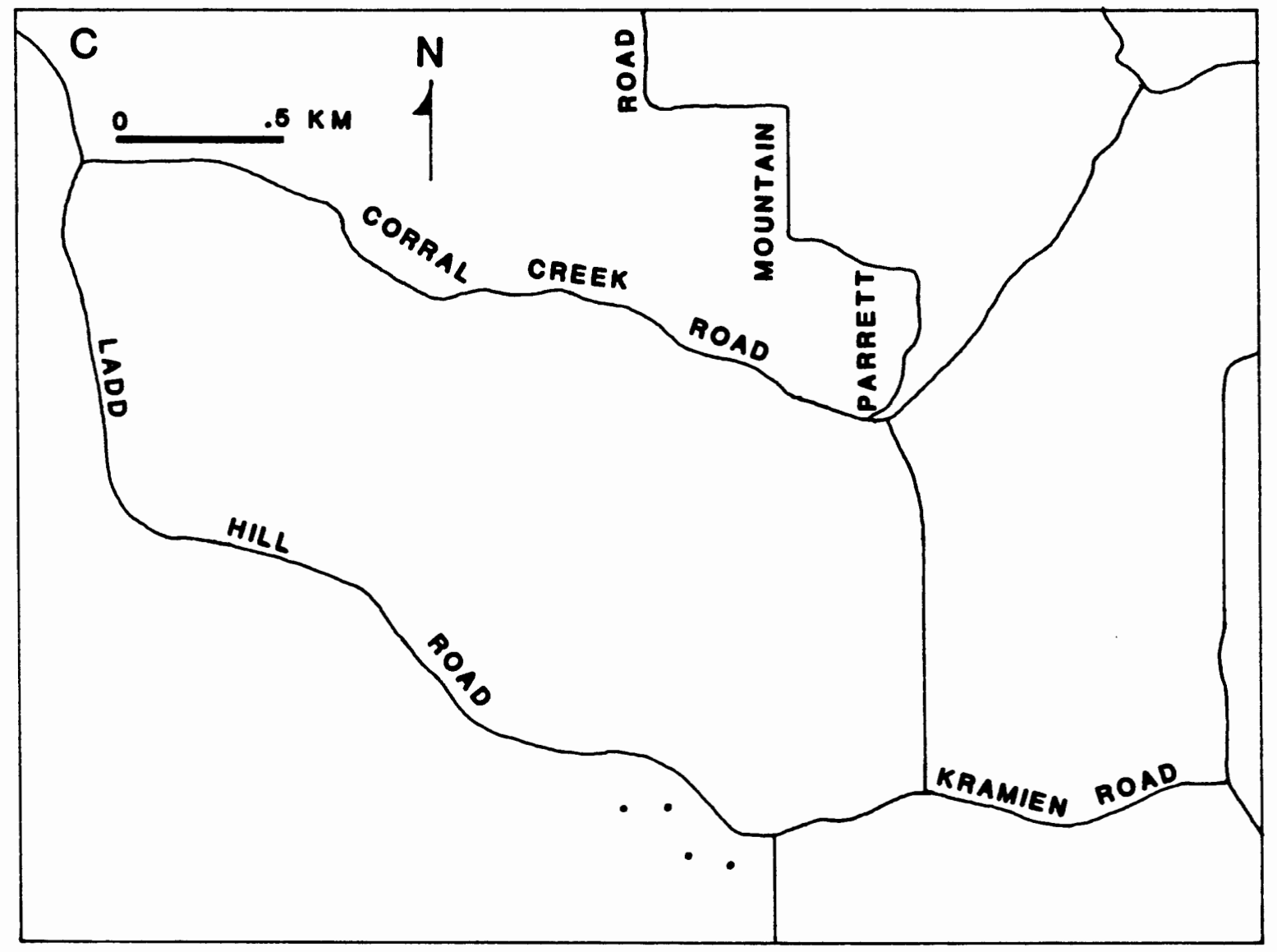




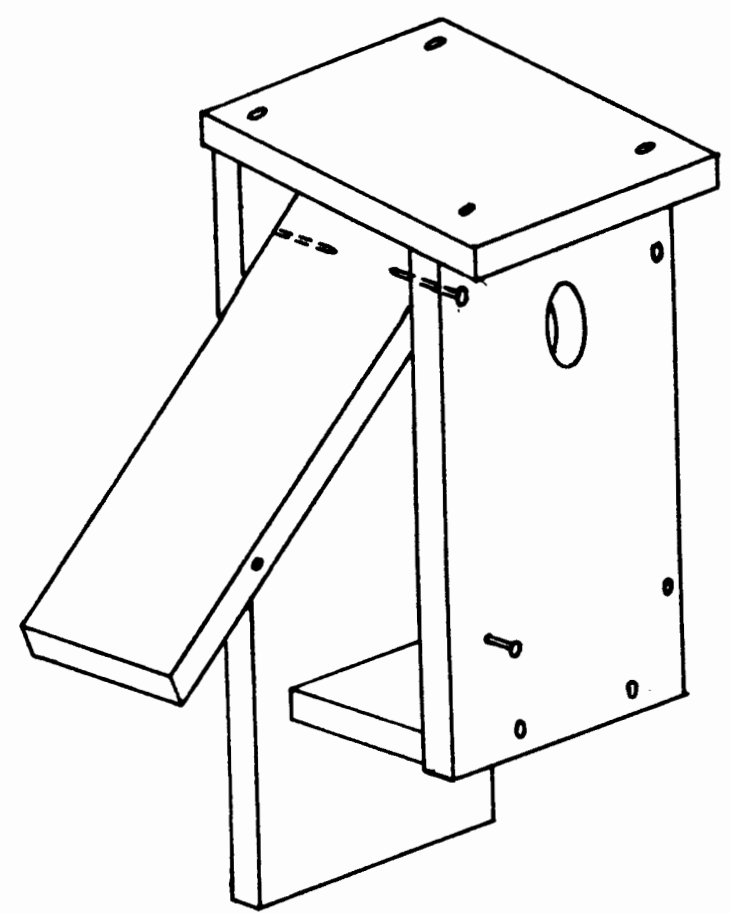

THAEE DIMENSIONAL VIEW

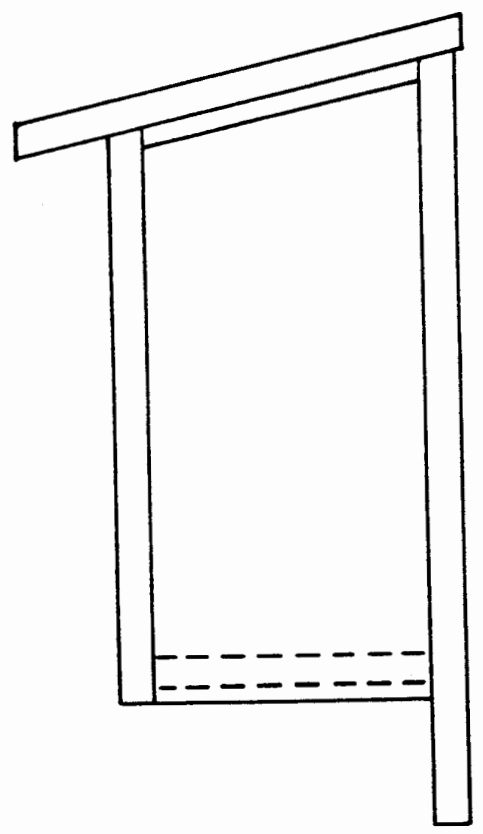

SIDE VIEW

Figure 2. Plans for a side-opening bluebird nest box. 
$19.9^{\circ} \mathrm{C}$ for July. Total precipitation for the year was 104 cm with $87 \%$, primarily rain, falling between October and May (U.S. Environmental Data and Information Service, 1970-1981).

The vegetation and land use on Parrett Mountain have been greatly modified by a long history of human activity (Prescott 1979, 1980). The study area encompassed homes, farms, orchards, oak (Quercus garryana) woods, and patches of coniferous forests where Douglas fir (Pseudotsuga menziesii) is dominant. The 80 nest boxes under observation had originally been erected in "good bluebird habitat". Sixty-six of the nest boxes were located on farmland which was used as pasture for cattle, horses, and sheep. Boxes were often mounted on fence lines between pasture and fields of hay, alfalfa, or vegetables. Some were placed on posts or trees in yards, fallow fields, or at the edge of oak woods. The other 14 nest boxes were located in walnut and prune orchards. 


\section{WESTERN BLUEBIRD BREEDING BIOLOGY}

\section{INTRODUCTION}

Little published information is available on Western Bluebird breeding biology. Knowledge of each of the 5 stages in the nesting cycle (nest-building, egg-laying, incubation, hatching, and nestling) is important in the study of avian species. If Western Bluebird population numbers are decreasing, statistics on bluebird reproduction may provide insight into the causes of the decline. Documentation is also essential for nest box trail management.

The purposes of this section are to analyze the breeding biology data for the Western Bluebirds studied on Parrett Mountain in 1979, and to examine several of the factors which may affect bluebird nest success.

\section{MATERIALS AND METHODS}

I began to locate and observe the nest boxes on Parrett Mountain on 25 April 1979. Some of the boxes used in this study were not found and under regular observation until June. Visits to boxes containing active bluebird nests were made every 2-3 days when possible through the course of the breeding season. Other boxes were visited 
each week. Over 64 days were spent in the study area. At each visit to a nest box the following information was noted: stage of nest-building, number of eggs, whether or not incubation had begun, number of nestlings (alive or dead), state of feather development, and presence and activity of adult bluebirds. Notes were made on nest box record cards (Figure 3 ) designed by the North American Bluebird Society (1979) and analyzed using the methods described in Appendix A.

\section{Statistics}

Frequency data were analyzed by the Pearson chi-square test for association (Hays 1963) unless otherwise stated. The Yates' correction for continuity was applied when there was 1 degree of freedom. The 0.05 level of significance was used for all comparisons.

Breeding Season

The breeding season was determined by calculating the date on which each clutch was completed and then totaling the number of such records for each 5 day period (Peakall $1970)$.

Clutch Size

Nest records were used in the determination of mean clutch size if they fell into 1 of the following categories described by White and Woolfenden (1973): a) nests visited at least once during the laying stage and again after 
H. PRESCOTT WESTERN BLUEBIRD ROUTE

MARCIA SIMS

Area $\longrightarrow$ Box — Land owner

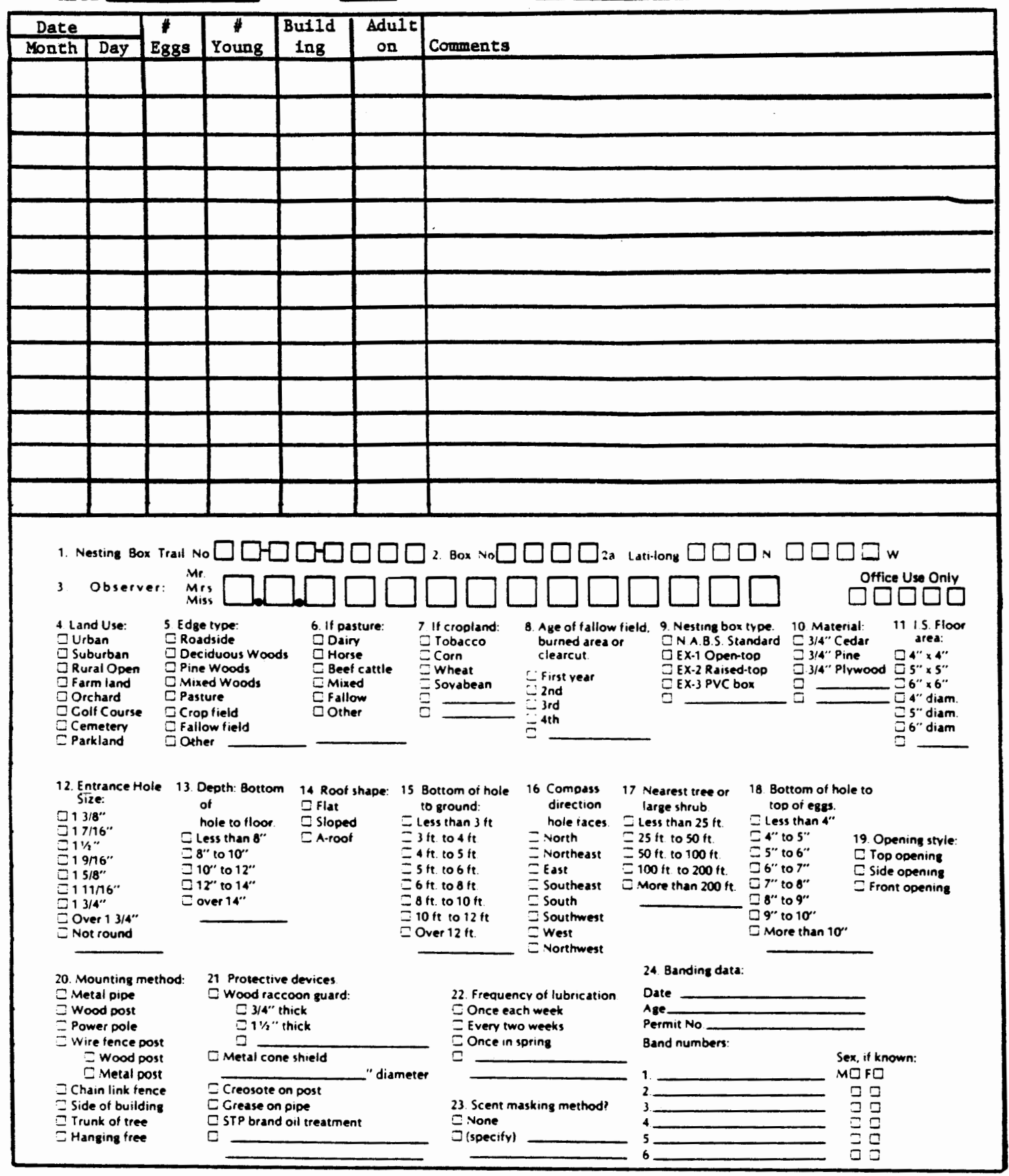

Figure 3. A nest box record card. 
sufficient time had passed for clutch completion (19 nests); b) nests observed at least twice with no increase in the number of eggs noted ( 2 nests); and c) nests seen only once during incubation, but again after hatching with the interim less than the incubation period (11 nests). Nest records were used only where the clutch had been completed. Clutches were considered complete if incubation had begun as seen by the presence of the female on the nest or was almost certainly underway (the eggs were warm) (Zwickel 1975), and there was no subsequent increase in the number of eggs present.

Incubation And Nestling Periods

The average incubation and nestling periods for Western Bluebirds were determined from data accurate to within 3 days for 22 nest attempts. The clutch completion date was defined as the day the last egg was laid. The hatching day was the day on which the majority of the eggs hatched. The fledging day was the day when 2 or more nestlings were known to have left the nest box and/or the box was empty and without signs of mishap or predation.

The duration of the incubation period was calculated by counting the number of days from the clutch completion date (Day 1) to the hatching day (Pinkowski 1974). The duration of the nestling stage was defined as that period from the day of hatching (Day 0 ) to the fledging date. When a range of days was given for either the clutch 
completion date, hatching date, or fledging date, then the length of the period was expressed as a range. The average length for both the incubation and nestling periods was then found.

Nest Sucess

Nest success was first calculated as the proportion of nests with complete clutches that fledged at least 1 young (Peakal1 1970). Mayfield's (1961, 1975) exposure method was then used. Based upon the number of days the nests were under observation, average mortality and survival rates were found for each stage of the nesting cycle. The procedure initially considered the nest as a whole unit; losses of individual eggs or nestlings from otherwise successful nests were then calculated. These individual losses were used to correct the overall nest success figured on a whole-nest basis. The details are explained in Appendix $B$.

Productivity was defined as the ratio of the total number of eggs laid to the total number of nestlings fledged (Herlugson 1980).

Mortality

Eggs or nestlings lost and young found dead in the nest were recorded. The appearance of the nest, presence of the adult bluebirds, and any other pertinent information suggesting the cause of death were also recorded. Mortalities were classified as described in Appendix A. 
Parasitism

The presence of insect larvae on bluebird nestlings or pupae in the nest material was noted (Watson and Amerson 1967).

Nine dead bluebird nestlings were removed from 3 different nests, and their intestinal tracts dissected and placed in vials of water for 2 hours. The intestines were preserved in formalin and later searched under the microscope for signs of endoparasites following instructions given by E.K. Eltzroth (personal communication). The specimens were then sent to L.L. Thompson-Cowley, Veterinary Diagnostic Laboratory, Oregon State University, who examined them for acanthocephalan parasites of the species Plagiorhynchus (Prosthorhynchus) formosus.

Nest Box Competition

Nest box use by other animal species was recorded. RESULTS

Breeding Season

Figure 4A shows the chronology of egg-laying for Western Bluebirds in 1979. The earliest extrapolated date of egg-laying was 23 April; the latest was 3 August. The onset of general laying, defined as the earliest date of the season on which 2 or more females laid their first eggs (Pinkowski 1977b), was 27 April.

The breeding season for 1979 was divided into 3 
Figure 4. Western Bluebird nesting calendar for Parrett Mountain, 1979. A. Histogram showing chronology of egg-laying (includes incomplete clutches, $\mathrm{n}=229$ ). B. Graph showing variation in clutch size with season. The dots date the initial egg of the indicated clutch size for 42 completed clutches. C. Breeding season expressed as a percentage of completed clutches for 5 day intervals $(n=42)$. 


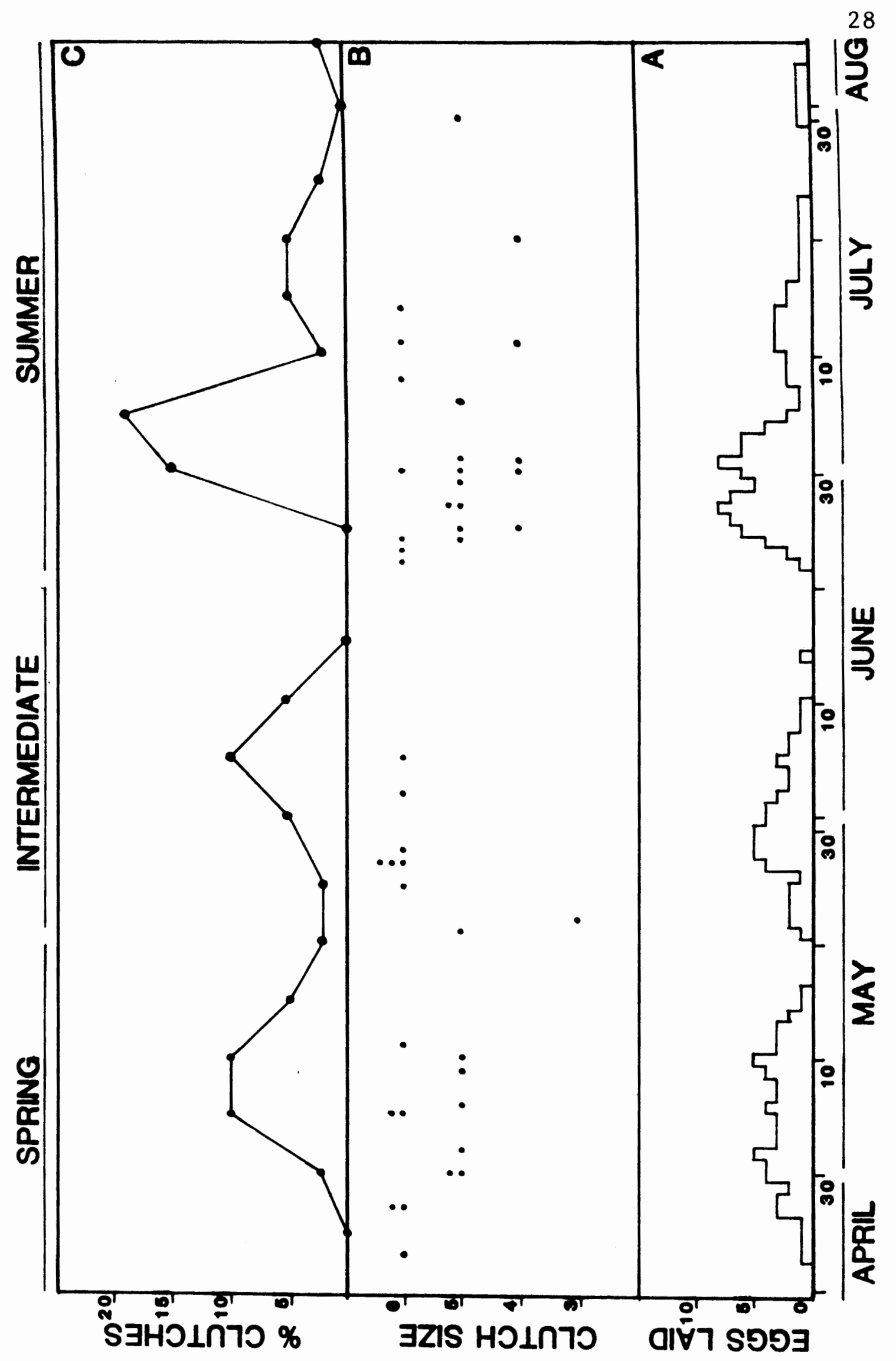


periods: 21 April-20 May (spring), 21 May-20 June (intermediate), and 21 June-10 August (summer). Nest attempts were placed in a period based on the first egg date. Including first and second broods and renesting, $28.5 \%$ of the clutches were completed in the spring, $21.4 \%$ in the intermediate period, and $50.0 \%$ during the summer (Figure 4B). The midpoint for egg-laying was 12 June. All of the clutches laid before that date contained 5 or 6 eggs, with the exception of a 3 egg clutch that later proved to be infertile. Clutch completion spanned 98 days in 1979.

Ninety-five per cent of the clutches were completed between 1 May and 31 July (Figure 4C). This represents the breeding season for Western Bluebirds observed in the study area in 1979. Three peak periods of egg-laying were seen, with most clutches being laid in the summer. Nestlings fledged from 19 May to 7 September.

\section{Clutch Size}

The mean clutch size for 32 Western Bluebird nests (172 eggs) was $5.4 \pm 0.8$ eggs (Table I). The distribution of clutch sizes was: 3 eggs $(3.1 \%), 4$ eggs $(12.5 \%), 5$ eggs $(28.1 \%), 6$ eggs $(56.3 \%)$. Clutch size ranged from 3 to 6 , with most clutches $(84 \%)$ containing 5 or 6 eggs. A least-square linear regression showed no difference in clutch size through the breeding season. 
TABLE I

SEASONAL VARIATION IN WESTERN BLUEBIRD CLUTCH SIZE ON PARRETT MOUNTAIN, 1979

\begin{tabular}{lccccccccc}
\hline & \multicolumn{7}{c}{ Number of } & Eggs per Clutch & \\
\cline { 2 - 7 } Date of First & Egg & 3 & 4 & 5 & 6 & $\mathrm{n}$ & $\%$ & Mean \pm SD \\
\hline Spring & 0 & 0 & 3 & 4 & 7 & 25 & $5.6 \pm 0.5$ \\
Intermediate & 1 & 0 & 0 & 7 & 8 & 22 & $5.6 \pm 1.1$ \\
Summer & 0 & 4 & 6 & 7 & 17 & 53 & $5.2 \pm 0.8$ \\
\hline Totals & 1 & 4 & 9 & 18 & 32 & 100 & $5.4 \pm 0.8$ \\
\hline
\end{tabular}


Incubation And Nestling Periods

The average incubation period for the Western Bluebird was calculated using 15 nest records that spanned the hatching stage. The mean was $14.4 \pm 2.0$ days. Therefore, 14 days was considered to be the normal length of the incubation period in this study and was used for extrapolations in the nest record analysis. A clutch completed 7 June had the longest incubation period of 21 days; the shortest interval, 12 days, was for a clutch completed 19 July.

The average nestling period, determined for 6 nest records, ranged from 17 to 23 days in length with a mean of $20.4 \pm 2.0$ days. Twenty days was assumed to be a normal nestling period and was used in the nest record analysis.

\section{Nest Success}

Thirty-five nestings $(70 \%)$ of 50 attempts were successful and fledged at least 1 young. Eleven of 18 single nest attempts were successful. Eight of 16 double nest attempts were completely (both nests) successful, and 8 had 1 success out of 2 . There were no nest boxes used by bluebirds where 2 nest attempts failed. Of 230 eggs laid, $149(65 \%)$ resulted in fledged young. Thirty-five $(83 \%)$ of 42 completed clutches fledged broods. Table II summarizes Western Bluebird reproduction statistics.

Table III shows Western Bluebird nest productivity compared to clutch size. Five egg clutches had the most 
TABLE II

WESTERN BLUEBIRD NEST DEVELOPMENT AND

BREEDING SUCCESS ON PARRETT MOUNTAIN, 1979

\begin{tabular}{ll}
\hline & Mean \pm SD(Sample Size);Range \\
\cline { 2 - 2 } Mean Clutch Size & $5.4 \pm 0.8(32) ; 3-6$ \\
Incubation Period (days) & $14.4 \pm 2.0(15) ; 12-21$ \\
Mean Brood Size & $4.8 \pm 1.3(29) ; 2-6$ \\
Hatch Rate & $83 \%(50)$ \\
Fertility Rate & $86 \%(29)$ \\
Mayfield's Hatching Success & $87 \%(31)$ \\
Nestling Period (days) & $20.4 \pm 2.0(6) ; 17-23$ \\
Mean Fledglings per Nest & $4.3 \pm 1.6(35) ; 1-6$ \\
Fledgling Success (eggs) & $65 \%(50)$ \\
Fledgling Success (nestlings) & $78 \%(35)$ \\
Nest Success & $70 \%(50)$ \\
Mayfield's Nest Success & $73 \%(45)$ \\
Productivity & $1.5(42)$ \\
\hline
\end{tabular}


TABLE III

CLUTCH SIZE AND NEST PRODUCTIVITY FOR WESTERN BLUEBIRDS BREEDING ON PARRETT MOUNTAIN, 1979

\begin{tabular}{ccccc}
\hline $\begin{array}{c}\text { Clutch } \\
\text { Size }\end{array}$ & $\begin{array}{c}\text { Number } \\
\text { of }\end{array}$ & $\begin{array}{c}\text { Number of } \\
\text { Noung Fledged }\end{array}$ & $\begin{array}{c}\text { Young Fledged } \\
\text { per }\end{array}$ Nest & $\begin{array}{c}\text { Nest } \\
\text { Productivity }\end{array}$ \\
\hline 3 & 1 & 0 & - & - \\
4 & 5 & 7 & 1.4 & 2.9 \\
5 & 16 & 68 & 4.3 & 1.2 \\
6 & 20 & 72 & 3.6 & 1.7 \\
\hline Totals & 42 & 147 & $\mathbf{x}=3.5$ & $\overline{\mathbf{x}}=1.5$ \\
\hline
\end{tabular}


fledglings per nest and were the most productive (the lowest eggs to fledged ratio).

\section{Mortality}

Table IV lists the sources of whole-nest mortality for 15 nests, and individual losses for 20 successful nests. Six eggs were lost from 1 abandoned completed clutch, 9 eggs were lost from 3 incomplete clutches, and 25 nestlings died in 6 broods. These 40 individuals constitute $49 \%$ of all the losses for the 1979 breeding season. One nest failed when the 3 eggs did not hatch after incubation, and 4 bluebird nests were found containing egg chips which suggested unsuccessful nest attempts. Thirty-three per cent of the complete nest failures were nests with eggs, $40 \%$ contained young, and $27 \%$ could not be positively determined. Most $(48 \%)$ of the individual losses from successful nests were due to eggs that did not hatch. Nestlings that disappeared from the nest represent the second important source of mortality.

Table $V$ compares the stage of the nesting cycle to the occurrence of mortality in each period of the breeding season. The nestling stage had the highest number of nest failures noted (absolute frequency). The egg-laying stage experienced the greatest relative frequency of mortality (total number of nest failures divided by the average length of each stage in days).

The following dead adult birds were removed from 
TABLE IV

WESTERN BLUEBIRD BREEDING SUCCESS AND SOURCES
OF MORTALITY ON PARRETT MOUNTAIN, 1979

\begin{tabular}{|c|c|c|}
\hline Whole-nest \& Individual Mortality & $\begin{array}{l}\text { Number } \\
\text { of Nests } \\
\end{array}$ & $\begin{array}{l}\text { Eggs or } \\
\text { Young } \\
\end{array}$ \\
\hline $\begin{array}{l}\text { Unsuccessful Nest Attempts } \\
\text { Abandoned Eggs } \\
\text { Unhatched Eggs } \\
\text { Nestling Death } \\
\text { Nest Failure } \\
\text { Totals }\end{array}$ & $\begin{array}{r}4 \\
1 \\
6 \\
4 \\
15\end{array}$ & $\begin{array}{r}15 \\
3 \\
25 \\
- \\
43\end{array}$ \\
\hline $\begin{array}{l}\text { Individual Losses From } \\
\text { Successful Nests } \\
\text { Unhatched Eggs } \\
\text { Eggs/Nestlings Lost At Hatching } \\
\text { Nestling Death-In-Nest } \\
\text { Nestlings Lost } \\
\text { Totals }\end{array}$ & $\begin{array}{r}8 \\
4 \\
2 \\
6 \\
20\end{array}$ & $\begin{array}{r}18 \\
4 \\
4 \\
12 \\
38\end{array}$ \\
\hline
\end{tabular}


TABLE V

TIMING OF WESTERN BLUEBIRD NEST FAILURES

ON PARRETT MOUNTAIN, 1979

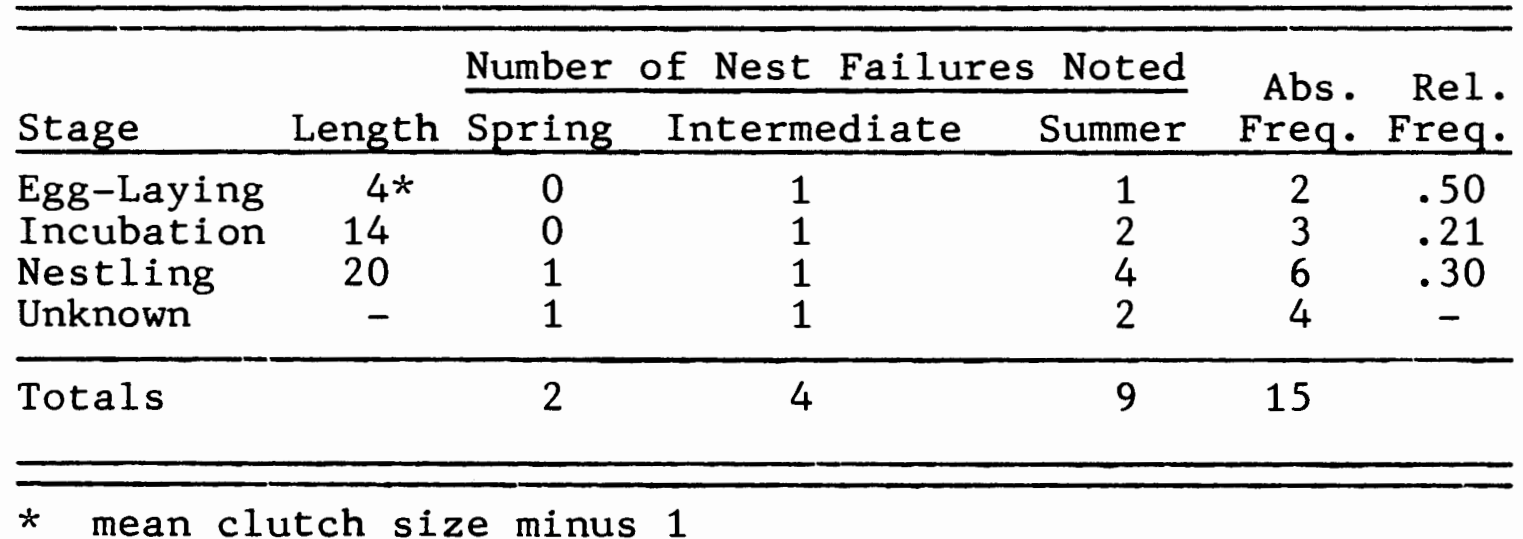


different nest boxes during the breeding season: 1 Tree Swallow, 2 Violet-green Swallows, and 2 Western Bluebirds.

$\underline{\text { Parasitism }}$

A nest from which bluebird young had fledged around 31 May contained a large number of pupae of a blowfly presumed to be Protocalliphora sp. (also known as Apaulina sp.) that is parasitic on bluebirds (Zeleny 1976). Blowfly larvae were noticed on the naked nestlings of 2 different second broods. Both nest attempts failed shortly thereafter, 1 around $28 \mathrm{July}$ and the other on 6 August. The examination of 9 Western Bluebird nestlings for acanthocephalan parasites was negative.

Nest Box Competition

There were 50 Western Bluebird nest attempts made in 34 of the 80 nest boxes. Tree Swallows had 15 nests in 14 boxes, and Violet-green Swallows had 12 nests in 11 boxes. Seven of these 25 boxes were also used by bluebirds. House Sparrows made 8 or more nest attempts. Four other bird species built nests in boxes. There were 11 unidentified unused nests found. Therefore, at least 89 avian nest attempts were made in the nest boxes located on Parrett Mountain in 1979. 
DISCUSSION

Breeding Season

No highly synchronized first peak for egg-laying was seen in 1979. The bimodal distribution (reflecting the tendency towards 2 broods per season) described by Peakall (1970), White and Woolfenden (1973), Pinkowski (1977b), and Herlugson (1980) was evident but not pronounced. The staggered timing of early nestings and the laying of repeat clutches following nest failures may have been responsible. The spring breeding period included bluebirds which laid a second clutch later in the season. Only 2 pairs in this group did not attempt a second nesting. In 1 case, an adult disappeared, and the nestlings subsequently died. In the second instance, a Violet-green Swallow began laying eggs in the nest box tire same day that the bluebird nestlings fledged. This bluebird pair may have renested outside the study area.

Pairs which began clutches during the intermediate period may not have nested successfully earlier, and many did not attempt a second nesting. Of those bluebirds that did lay 2 sets of eggs, 1 pair abandoned their second set; 1 pair laid an infertile first clutch and then a fertile second clutch; the second brood of another pair was abandoned, possibly due to the death of the female; 1 pair may have raised 2 broods in nearby nest boxes; and 1 pair did have 2 successful fledgings in the same box. 
Bluebirds which nested in the summer breeding period often had already raised 1 brood in the box. Herlugson (1980) found that 2 main periods of breeding activity for Western Bluebirds represented pairs of birds raising 2 successive broods. Pinkowski (1974) obtained similar results in his analysis of the different Eastern Bluebird breeding periods.

Timing of Laying, Egg Color, And Clutch Size

Two bluebird eggs appeared to have been laid in 1 day in second clutches at 2 different nest boxes during this study. Normally $1 \mathrm{egg}$ is laid per day. It is difficult to interpret such nest records if daily visits to the nest box are not made (Pinkowski 1974).

In 1979,1 bluebird nest consisted of 2 very pale blue eggs and 4 eggs that were almost white in color. All of these eggs hatched. Another nest held 2 very pale blue eggs and 1 white misshapen egg. These eggs were brooded for about 30 days, and then the nest and eggs were removed. The female laid a second set of normally pigmented eggs which subsequently hatched. Nine per cent of the eggs laid by Eastern Bluebirds were albinistic in a survey done by Laskey (1939). Power (1966) found that $8 \%$ of the Mountain Bluebird eggs in his research area were whitish, and only 1 was fertile. The total number of pale eggs laid on Parrett Mountain in 1979 is not known as some nests were found after the eggs hatched. However, based on the available data, the 
incidence of albino infertile eggs appears to be low for Western Bluebirds found in the study area.

There was no change in mean clutch size for Western Bluebirds through the breeding season. This contrasts with a study of cavity nesters by Erskine and McLaren (1976), and of Eastern Bluebirds by McKnight (1973), in which clutch size decreased with later dates of nest initiation. Clutch size for multi-brooded species often increases to a peak at mid-season and then decreases (White and Woolfenden 1973). Herlugson (1980) noted this trend for both Western and Mountain Bluebirds.

Table VI lists data from other Western Bluebird nest box studies. The calculations are based on the use of all nests which contained 1 or more bluebird eggs, including incomplete clutches. Some nest box trails were checked less frequently than others which may have biased the results. The mean clutch size of 4.6 eggs/nest $(n=50)$ for the 1979 breeding season on Parrett Mountain is comparable to the other studies.

Incubation And Nestling Periods

The incubation period of 14 days and the nestling period of 20 days determined in this study are comparable to data for Western Bluebirds nesting on other bluebird trails in the Willamette Valley (Elzroth, Prescott, and Prigge, personal communications). 


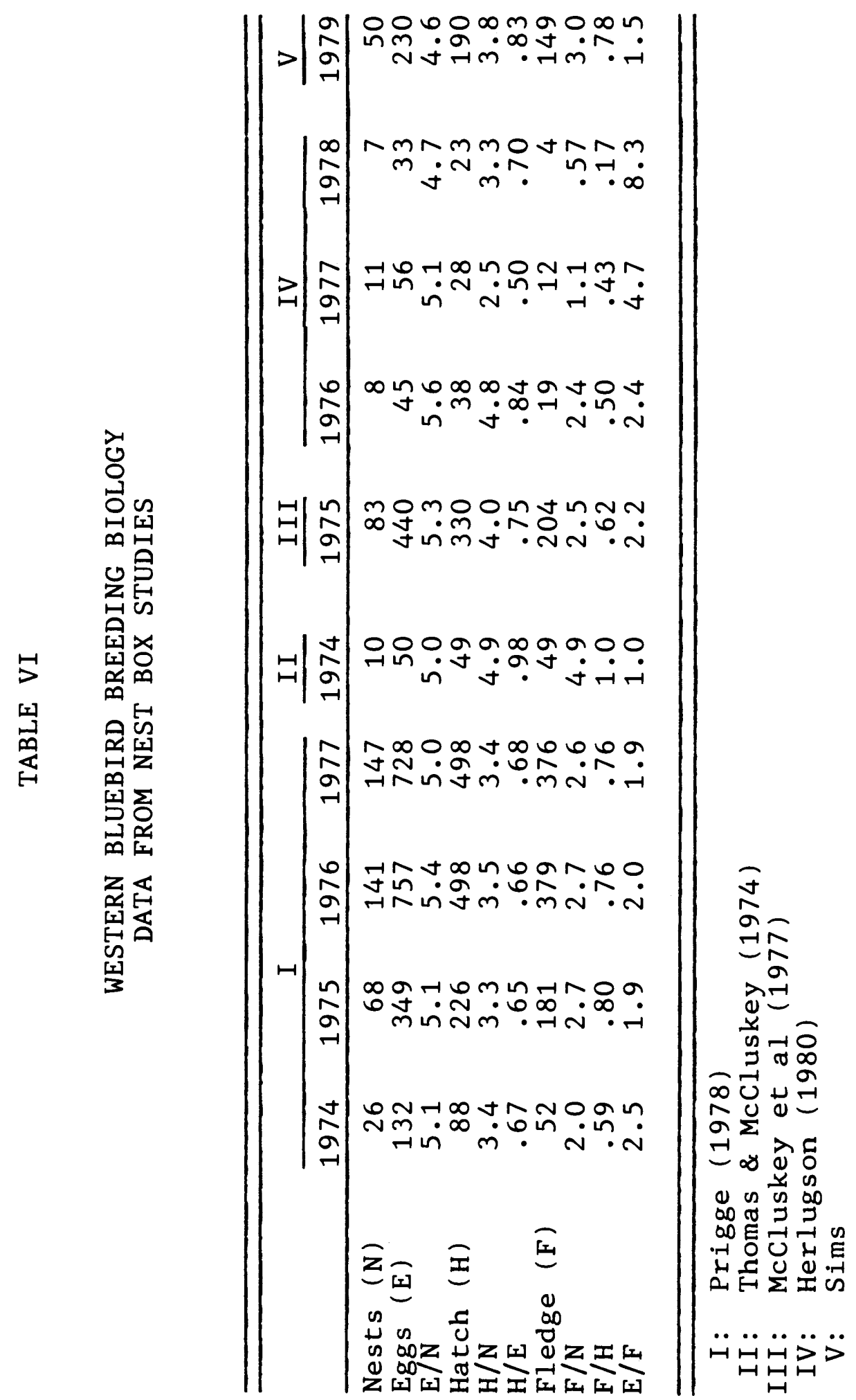


Nest Success

A high (70\%) level of nest success was indicated for the small sample of Western Bluebird eggs and nestlings available for analysis in this project. This is greater than the average of $66 \%$ that Nice (1957) reported in a summary of nest success for cavity nesters. The Parrett Mountain statistics (Table VI) are well within the range recorded for Western Bluebirds. The number of young that fledged per nestlings hatched $(78 \%)$ is similar to data from a Eugene area bluebird trail (Prigge 1978) and higher than Herlugson's (1980) results for Western Bluebirds in Washington.

Mayfield's method of calculating nest success gave a figure of $73 \%$ (Appendix B). His assumption that a constant mortality rate exists through the nesting cycle and for all nests may not always be correct (Green 1977). White and Woolfenden (1973) thought that nest success was higher early in the season due to low levels of predation. Infrequent visits during the spring could lead to an underestimate of nest success. However, Klett and Johnson (1982) considered this possibility to be insignificant with as much as a twofold difference in daily mortality rates between subpopulations of nests. They found Mayfield's method to be appropriate for nests visited up to 15 days apart. Therefore, the use of Mayfield's method in this study is acceptable. 
Human visitation to nest boxes may increase the chance of predation and therefore lower nest success. Bart (1977) found that the loss of individual eggs/nestlings was not affected by visits to the nest during the incubation or nestling periods. But the total mortality rate (loss of the entire clutch or brood) was higher the first day after a visit than on subsequent days. Gottfried and Thompson (1978) determined that visits to open nests had no effect on nest success or failure. The potential for increased predation due to human visitation certainly exists on the Parrett Mountain trail, which is monitered by route managers, visited by community groups, and where some individual boxes are checked regularly by property owners. Some predation during the final days of the nesting cycle may go unnoticed, with the result that nest success is overestimated (Best and Stauffer 1980). According to Kibler (1969), the average losses to predators on an unguarded bluebird nest box project may run $25 \%$ or higher. No predator deterrents or scent masking devices were used in 1979 .

Nest productivity was also examined. A mean productivity ratio (E/F) of 1.5 eggs laid for every nestling that fledged (Table VI) was found for Parrett Mountain in 1979. Herlugson's (1980) combined mean productivity ratio was 3.8. This suggests that Western Bluebirds in Washington laid 2.3 more eggs than Western Bluebirds on Parrett 
Mountain to successfully fledge one young. Parrett Mountain nest productivity was comparable to values found for other Oregon nest box studies.

\section{Mortality}

Forty-three bluebird eggs/nestlings were lost as part of the death of complete clutches or broods. Nestling death was the largest category of whole-nest mortality. The rate of mortality was highest during the egg-laying stage, but more mortalities actually occurred during the nestling stage. Over half of these deaths were in the summer period. Pinkowski (1977a) also found that the daily rate of nest loss was greatest in the egg-laying stage. His total per cent of failure for Eastern Bluebird nests was higher during the incubation stage. In contrast, Peakall (1970) and White and Woolfenden (1973) found more Eastern Bluebird losses occurred during the nestling period. Increased activity by the adults and nestlings may raise the level of predation for nests with nestlings.

Failure of eggs to hatch represents the primary source of individual losses seen in successful Western Bluebird nests. Eight per cent of the eggs laid and incubated till hatching day on Parrett Mountain failed to hatch. Such eggs are usually believed to be infertile. The figures agree with Peakall's (1970) who found that infertility for Eastern Bluebirds was highly variable with a range of $2.6-12 \%$ ( $x<$ $7 \%$ ). He found no pattern or seasonal variation for 
infertility or overall individual mortality.

An event related to the failure of an egg in a clutch

to hatch is the unexpected loss of 1 or more eggs/hatchlings at hatching. Mcknight (1973) suggested that the female either identified sterile eggs and threw them out at hatching, or dead hatchlings were immediately removed. On Parrett Mountain, $2 \%$ of the eggs in successful nests disappeared at hatching. White and Woolfenden (1973) attributed $4 \%$ of their losses from successful Eastern Bluebird nests to the disappearance of individual nestlings.

\section{Parasitism}

Heavy infestations of Protocalliphora sialia

larvae are felt to weaken and possibly kill Eastern Bluebird young (Zeleny 1976), but there are few references to the relationship between blowflies and Western Bluebirds. Protocalliphora flies were observed by Law (1929) circling the entrances of cavities containing nuthatch, chickadee, and bluebird (presumably Sialia mexicana) young on many occasions. Protocalliphora splendida larvae were found in House Sparrow nests at Seattle, Washington (Guberlet and Hotson 1940). Pinkowski (1977a) compared the degree of parasitism by Protocalliphora sialia for Eastern Bluebird nestlings found in natural cavities and nest boxes. He found more larvae and pupae per parasitized nest in nest boxes, possibly because they were larger cavities and contained more nesting material. He also positively 
correlated the number of parasites with the number of nestlings in a nest and found significantly more blowfly parasites in nests where young were deprived of food.

Starvation due to the death of an adult or to abandonment may have been the primary cause of death for nestlings found in 2 nests obviously infested with blowfly larvae, but the cause of nestling deaths was never determined. The appearance of large numbers of blowfly larvae in a nest box may be an indication of poor nestling health or lowered adult attentiveness.

No acanthocephalan parasites were found in the Western Bluebird nestlings examined. The dead adult Western Bluebirds recovered on the nest box route were too decayed for analysis. Heavy infestations of acanthocephalan parasites have been a contributing cause of death for adult Western Bluebirds found on Willamette Valley nest box trails (Thompson-Cowley et al 1979, Eltzroth 1980, and Eltzroth et al 1980).

Nest Box Competition

Prescott (1979) reported that Tree and Violet-green Swallows used more boxes on the Portland area trails than all other nest box competitors combined. He thought that swallows were able to aggressively displace bluebirds from desired boxes. His 1977 records indicated that for every 5 nest boxes used by bluebirds, 3 were used by swallows. The 1979 Parrett Mountain data support this, but there was 
little evidence of swallows driving away bluebirds that had already begun to nest in a box. In 1 instance, a bluebird egg was laid and later abandoned in a nest box containing an old moss nest. Several days later a Violet-green Swallow laid 4 eggs in the nest and began incubating. The bluebird egg hatched first, and all of the nestlings were cared for until 5 days after hatching when the contents of the nest disappeared. It is not known if the swallows actually caused the bluebirds to abandon their egg. In another case, a Violet-green Swallow began laying her eggs in a bluebird nest the same day the bluebird nestlings fledged. The bluebird pair did not attempt a second nest in this box. Herlugson (1980) found that Mountain Bluebird attempts to evict Western Bluebirds from nest boxes were unsuccessful, as were attempts by Western Bluebirds to evict Mountain Bluebirds.

Several nest boxes on Parrett Mountain were grouped in pairs on nearby trees or in clusters along fence lines. House Sparrows, Western Bluebirds, Violet-green and Tree Swallows used adjoining boxes. Boone (1982a, 1982b), Prescott (1982), and Prigge (1981, 1982) examined the effect on interspecific competition of the proximity of nest boxes to 1 another. From their results, it is still unclear whether the use of paired nest boxes actually results in more bluebirds per given area, although cavity nesting species may increase in number. 
While nest box competition between Western Bluebirds and swallows does occur on Parrett Mountain, its effect on bluebird population numbers and nest success is difficult to assess considering that almost half of the nest boxes available remained empty throughout the 1979 breeding season. 
WESTERN BLUEBIRD NEST SITE CHARACTERISTICS

\section{INTRODUCTION}

A critical aspect of avian reproduction is the selection of an appropriate nest location and territory. Such action determines the environmental conditions to which the adults, eggs, and nestlings are exposed. The supply of food, water, and perches becomes fixed. The surrounding habitat, the proximity of 1 cavity to another, and the cavity dimensions influence the amount of inter and intraspecific competition experienced by cavity nesting species. Sites selected for nest placement vary in their probability for success (Best and Stauffer 1980). Natural selection should favor individuals that choose nest site characteristics which maximize nest success (Caccimise 1977, Pinkowski 1979b). Presumably, nest placement has evolved in response to such factors as predation, resource availability, and microclimate (Walsberg 1981).

Nest box designs have been studied in detail. Jackson and Tate (1974) analyzed nest box interior and exterior colors, materials, and location. McComb and Noble (1981a) compared the temperature, relative humidity, solar radiation, and light found inside nest boxes with that of natural cavities. The height of the entrance, box design, 
inside temperature, and bird usage were examined by Norman and Riggert (1977). Havera (1979) and Kendeigh (1961) measured mean temperatures inside nest boxes. Entrance hole size and interior colors were varied by Lumsden (1976) to determine bird preferences.

Floor dimensions were found to influence clutch size (Karlsson and Nilsson 1977). Reproductive success was affected by the insulating properties of nest boxes (O'Conner 1978). Research with Eastern Bluebirds (Pinkowski 1979b) indicated that age and nest success were important factors in nest site selection, but natal nest site imprinting was not. Herlugson's (1981) work with Mountain Bluebirds suggested that nest box selection was influenced by age, sex, natal nest box type, and previous breeding experience.

Does the design of a nest box affect the success of a bluebird nest? Do Western Bluebirds prefer nest sites with specific qualities? If so, can these be identified and a relationship shown between them and reproductive success? The purposes of this section are to quantify a variety of nest box characteristics, and compare them to bluebird usage and nest success.

\section{MATERIALS AND METHODS}

Nest site characteristics for each nest box were measured and recorded on a nest box record card (Figure 3). 
Nest Box Location

The area immediately around each nest box was classified by land use and edge type (North American Bluebird Society 1979).

Nest Box Design

Nest box type, materials, roof shape, opening style, mounting structure, and protective devices were noted. Inside floor dimensions, entrance hole diameter, and distance from the bottom of the entrance hole to the floor and to the ground were measured.

The 80 nest boxes studied in 1979 were of standard bluebird box design (Figure 2). All the roofs were sloped except for 6 boxes classified as open-top because the roof had been removed and the top opening covered with hardware cloth. Boxes were constructed of a variety of wood types and thicknesses, but $1.3 \mathrm{~cm}$ and $1.6 \mathrm{~cm}$ exterior plywood and $1.9 \mathrm{~cm}$ and $2.5 \mathrm{~cm}$ Douglas fir were most common. The contents of each box could be viewed by means of a movable front ( 22 boxes) or side ( 57 boxes) pane1. One box did not open, but had a large hole on the side which permitted observations. The mean inside floor area was $158.5 \pm 7.9$ $\mathrm{cm}^{2}$ (range $119.4-164.5 \mathrm{~cm}^{2}$ ). All the boxes originally had standard $(3.8 \mathrm{~cm}$ diameter) entrance holes except 1 with a $3.2 \mathrm{~cm}$ hole. In 1979,13 entrance holes were no longer round due to changes made by birds and mammals. The mean distance from the bottom of the entrance hole to the floor 
of the nest box was $17.1 \pm 1.7 \mathrm{~cm}$ (range $14.0-21.0 \mathrm{~cm}$ ).

Nest Box Placement

The nest boxes were mounted on tree trunks (47), wood posts (3), or fence posts (30) at a mean height of $1.87 \pm$ $.20 \mathrm{~m}$ (range $1.14-2.34 \mathrm{~m}$ ). The distance from the entrance hole to the nearest tree or large shrub assumed to be visible by nestlings was measured. The mean distance was $14.58 \pm 11.0 \mathrm{~m}(\mathrm{n}=66$, range $1.60-48.77 \mathrm{~m})$. Fourteen boxes were located more than $60 \mathrm{~m}$ from any trees. These boxes were on or near fence lines. All of the boxes were within $0.5 \mathrm{~km}$ of a stand of trees. The distance from the nest box to the nearest building in any direction was measured directly or estimated from aerial photographs of the study area. Forty-nine nest boxes were within $100 \mathrm{~m}$ of a building.

\section{Entrance Orientation}

The direction that the entrance hole faced was recorded to the nearest degree azimuth with a compass and corrected to true north. The data were placed in $490^{\circ}$ quadrants centered on the compass points, and tested for nonrandom dispersion with a chi-square test. The mean entrance direction for the nest boxes was calculated using Batschelet's (1965) method.

\section{Solar Index}

The amount of sunlight to which each nest box was 
exposed was quantified by taking a reading immediately above the roof of each nest box with a Star pyranometer. This was done between 11:00 and 13:00 PDT during a 3-day period of good weather. The nest box reading was then divided by a reading taken nearby in full sunlight. The result was used as an index of solar radiation with 1.00 representing boxes in full sunlight.

Nest Box Density Index

Nest box locations mapped on aerial photographs were used to construct an index of nest box density. A circle with radius $125 \mathrm{~m}$ ( area $=49087 \mathrm{~m}^{2}$ ) was centered around each nest box, and the number of nest boxes included within the circle was used as the index.

Nest Site Characteristics And Mortality

Mean entrance height, solar index, nest box density index, and per cent of boxes mounted on trees were found for all the nest boxes which experienced Western Bluebird mortalities in the following categories (described in Appendix A): abandoned eggs, whole-nest nestling death, nest failure, individual eggs/nestlings lost at hatching, and individual nestlings lost. These figures were then compared to the means generated for nest boxes from which bluebird nestlings successfully fledged.

Nest boxes which had experienced bluebird mortalities were then divided into 2 groups (tree or post) determined by 
the structure to which they were mounted. These boxes were further placed into the 3 breeding season periods based on first egg dates. Incidents of mortality due to unhatched eggs or nestlings death-in-nest were not included.

\section{Nest Box Temperatures}

Temperature studies were conducted at 4 locations on Parrett Mountain (Figures 1A, 1B). Changes in ambient and nest box temperatures were examined. Six additional boxes were placed where needed to study the effects of nest box orientation, shading, and bluebird use on nest box temperatures. Each temperature study site had at least 1 Western Bluebird brood fledge from a nest box in 1979. Nest boxes used in the temperature studies all contained empty grass Western Bluebird nests.

A calibrated Model 46 TUC Tele-thermometer with probes was used to take series of hourly nest box and ambient temperatures at Sites 1, 3, and 4. A probe was taped inside each nest box with the sensor touching the nest material. External ambient temperatures were read with the probe shaded and protected from the wind. At Site 1, nest box and ambient temperatures were recorded for 6 hours beginning at $7: 30$ on 30 June, and for 7 hours beginning at 11:00 on 20 July. Temperatures were taken hourly from 11:00 to 14:00 on 6 August, and from 10:30 to 14:30 on 16 August at Site 3 . Site 4 consisted of a white nest box from which 2 broods of 6 and 4 fledged. Readings began at 10:40 on 16 August, 8 
days before the second brood of nestlings fledged.

Temperatures were recorded to the nearest $0.1^{\circ} \mathrm{C}$ with Taylor maximum-minimum thermometers at Sites 1, 2, and 3 . Each thermometer was compared with a standard thermometer and correction factors established when necessary. One thermometer was placed inside each box with the bottom level with the nest cup. Another thermometer was mounted nearby in the shade at approximately the same height. Thermometers were reset whenever temperatures were recorded.

\section{RESULTS}

Nest Box Location

The land use categories (Table VII) were examined to determine if bluebirds selected boxes by habitat in a nonrandom manner. The categories proved not to be useful due to the diversity of the study area, the small sample size, and the bluebirds' mobility in relation to foraging strategies. No relationship was seen between nest box location and land use and nest box use or breeding success.

Nest Box Design

Table VIII shows nest box design characteristics and the number of Western Bluebird nest attempts and successes for each class. The variability in nest box design was considered to be too small to influence nest box selection or nest success. 
TABLE VII

NEST BOX LOCATION AND WESTERN BLUEBIRD USE ON PARRETT MOUNTAIN, 1979

\begin{tabular}{|c|c|c|c|c|}
\hline & \multicolumn{2}{|c|}{ Nest Boxes } & \multicolumn{2}{|c|}{ Bluebird } \\
\hline & $\begin{array}{c}\text { Used By } \\
\text { Bluebirds }\end{array}$ & $\begin{array}{c}\text { Total } \\
\text { Available } \\
\end{array}$ & $\begin{array}{c}\text { Successful } \\
\text { Nests }\end{array}$ & $\begin{array}{c}\text { Nest } \\
\text { Attempts }\end{array}$ \\
\hline $\begin{array}{l}\text { Land Use: } \\
\text { Farm } \\
\text { Orchard }\end{array}$ & $\begin{array}{r}26 \\
8\end{array}$ & $\begin{array}{l}66 \\
14\end{array}$ & $\begin{array}{l}22 \\
13\end{array}$ & $\begin{array}{l}30 \\
20\end{array}$ \\
\hline $\begin{array}{l}\text { Edge Type: } \\
\text { Pasture/Crop } \\
\text { Orchard } \\
\text { Fallow Land } \\
\text { Deciduous Woods } \\
\text { Yard }\end{array}$ & $\begin{array}{r}20 \\
6 \\
5 \\
0 \\
3\end{array}$ & $\begin{array}{r}52 \\
9 \\
13 \\
2 \\
4\end{array}$ & $\begin{array}{r}22 \\
7 \\
3 \\
0 \\
3\end{array}$ & $\begin{array}{r}30 \\
10 \\
6 \\
0 \\
4\end{array}$ \\
\hline $\begin{array}{l}\text { Pasture: } \\
\text { Cattle } \\
\text { Horses } \\
\text { Other Animals }\end{array}$ & $\begin{array}{r}10 \\
4 \\
6\end{array}$ & $\begin{array}{r}33 \\
9 \\
10\end{array}$ & $\begin{array}{r}11 \\
5 \\
6\end{array}$ & $\begin{array}{r}16 \\
5 \\
9\end{array}$ \\
\hline
\end{tabular}


TABLE VIII

NEST BOX DESIGN AND WESTERN BLUEBIRD USE
ON PARRETT MOUNTAIN, 1979

\begin{tabular}{|c|c|c|c|c|}
\hline & \multicolumn{2}{|c|}{ Nest Boxes } & \multicolumn{2}{|c|}{ Bluebird } \\
\hline & $\begin{array}{c}\text { Used By } \\
\text { Bluebirds }\end{array}$ & $\begin{array}{c}\text { Total } \\
\text { Available } \\
\end{array}$ & $\begin{array}{c}\text { Successful } \\
\text { Nests }\end{array}$ & $\begin{array}{c}\text { Nest } \\
\text { Attempts } \\
\end{array}$ \\
\hline $\begin{array}{l}\text { Nest Box Type: } \\
\text { NABS Standard } \\
\text { EX-L Open Top }\end{array}$ & $\begin{array}{r}34 \\
0\end{array}$ & $\begin{array}{r}74 \\
6\end{array}$ & $\begin{array}{r}35 \\
0\end{array}$ & $\begin{array}{r}50 \\
0\end{array}$ \\
\hline $\begin{array}{l}\text { Opening Style: } \\
\text { Side } \\
\text { Front } \\
\text { None }\end{array}$ & $\begin{array}{r}22 \\
11 \\
1\end{array}$ & $\begin{array}{r}57 \\
22 \\
1\end{array}$ & $\begin{array}{r}24 \\
10 \\
1\end{array}$ & $\begin{array}{r}32 \\
16 \\
2\end{array}$ \\
\hline $\begin{array}{l}\text { Inside Floor } 2^{\text {Are }} \\
\text { 110-119 } \mathrm{cm}^{2} \\
120-129 \\
130-139 \\
140-149 \\
150-159 \\
160-169\end{array}$ & $\begin{array}{r}0 \\
0 \\
0 \\
0 \\
2 \\
32\end{array}$ & $\begin{array}{r}1 \\
0 \\
2 \\
0 \\
9 \\
68\end{array}$ & $\begin{array}{r}0 \\
0 \\
0 \\
0 \\
2 \\
33\end{array}$ & $\begin{array}{r}0 \\
0 \\
0 \\
0 \\
3 \\
47\end{array}$ \\
\hline $\begin{array}{l}\text { Entrance Hole Di } \\
3.2 \mathrm{~cm} \\
3.8 \\
3.8+\end{array}$ & $\begin{array}{r}\text { ter: } \\
0 \\
31 \\
3\end{array}$ & $\begin{array}{r}1 \\
66 \\
13\end{array}$ & $\begin{array}{r}0 \\
31 \\
4\end{array}$ & $\begin{array}{r}0 \\
45 \\
5\end{array}$ \\
\hline $\begin{array}{l}\text { From Bottom of } \\
\text { Hole To Floor: } \\
14.0-16.4 \mathrm{~cm} \\
16.5-17.4 \\
17.5-21.0\end{array}$ & $\begin{array}{r}7 \\
14 \\
13\end{array}$ & $\begin{array}{l}22 \\
27 \\
31\end{array}$ & $\begin{array}{r}7 \\
13 \\
15\end{array}$ & $\begin{array}{l}10 \\
20 \\
20\end{array}$ \\
\hline
\end{tabular}


Nest Box Placement

The mounting structure, entrance height, and the distance from each nest box to nearby trees and buildings were compared to bluebird use and the number of bluebird nest attempts in Table IX. Data were analyzed for association with chi-square tests. None of the variables was significant for nest box use or nest success $(p>0.05)$.

\section{Entrance Orientation}

The circular distribution of nest box entrances is shown in Figure 5. Twenty-seven boxes in the study area faced north, 27 faced east, 14 faced south, and 12 faced west. The mean entrance orientation for the 80 boxes was $59^{\circ}$. A chi-square test showed a nonrandom orientation $\left(\mathrm{x}^{2}=\right.$ 9.9, $\mathrm{p}<0.025,3 \mathrm{df}$ ) for the boxes located on Parrstic Mountain. More nest boxes faced northeast. Table IX lists the entrance orientation for boxes used by Western Bluebirds and shows the distribution of nest attempts and successful nests. Data were tested with chi-square tests for association. Results were not significant for the distribution of boxes used by Western Bluebirds, nor was there a correlation between nest attempts and/or successful nests and orientation.

Western Bluebird nest attempts were then divided into the 3 breeding season periods based on known first egg dates $(n=45)$. These were plotted on a circular graph (Figure 6) showing entrance orientation and the solar index of each 
TABLE IX

NEST BOX PLACEMENT AND WESTERN BLUEBIRD USE

ON PARRETT MOUNTAIN, 1979

\begin{tabular}{cccc}
$\frac{\text { Nest }}{\text { Boxes }}$ & & \multicolumn{2}{c}{ Bluebird } \\
Bsed By & Total & Successful Nest \\
Bluebirds Available & Nests & Attempts
\end{tabular}

Entrance Height:

$\begin{array}{lrrrr}1.14-1.74 \mathrm{~m} & 8 & 18 & 6 & 11 \\ 1.75-2.04 & 21 & 48 & 22 & 30 \\ 2.05-2.34 & 5 & 14 & 7 & 9\end{array}$

Mounting Structure:

Wood Post

Fence Post

Tree Trunk

From Entrance To

Nearest Tree:

$$
\begin{aligned}
& 0.00-7.40 \mathrm{~m} \\
& 7.50-15.49 \\
& 15.50-30.49 \\
& 30.50+
\end{aligned}
$$

7

9

9

9

20

14

12

11

4

Solar Index:
21

2

0

11
From Box To

earest Building:

$0-100$
$101+$

Entrance 8rientation:

$$
\begin{aligned}
& 316-45^{\circ} \mathrm{N} \\
& 46-135 \mathrm{E} \\
& 136-225 \mathrm{~S} \\
& 226-315 \mathrm{~W} \\
& \\
& \\
& 1 \text { ar Index : } \\
& .00-0.25 \\
& .26-0.50 \\
& .51-0.75 \\
& .76-1.00
\end{aligned}
$$$$
\text { E }
$$$$
\text { W }
$$$$
7
$$

22

20

18

20
6
10
8

11

5
9

21
6

11

33

\section{1 \\ 9}

.

49

22

30

13

20

27

27

14

12

10
13
4
8

17

17

6

10

Nest Box Density Index:

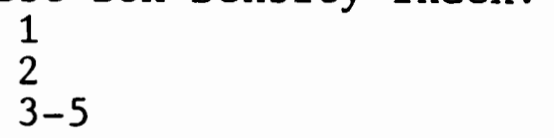

$18 \quad 30$

32

14
2

18

21

30

1

3

0

17

13

2

20

28

12

18 


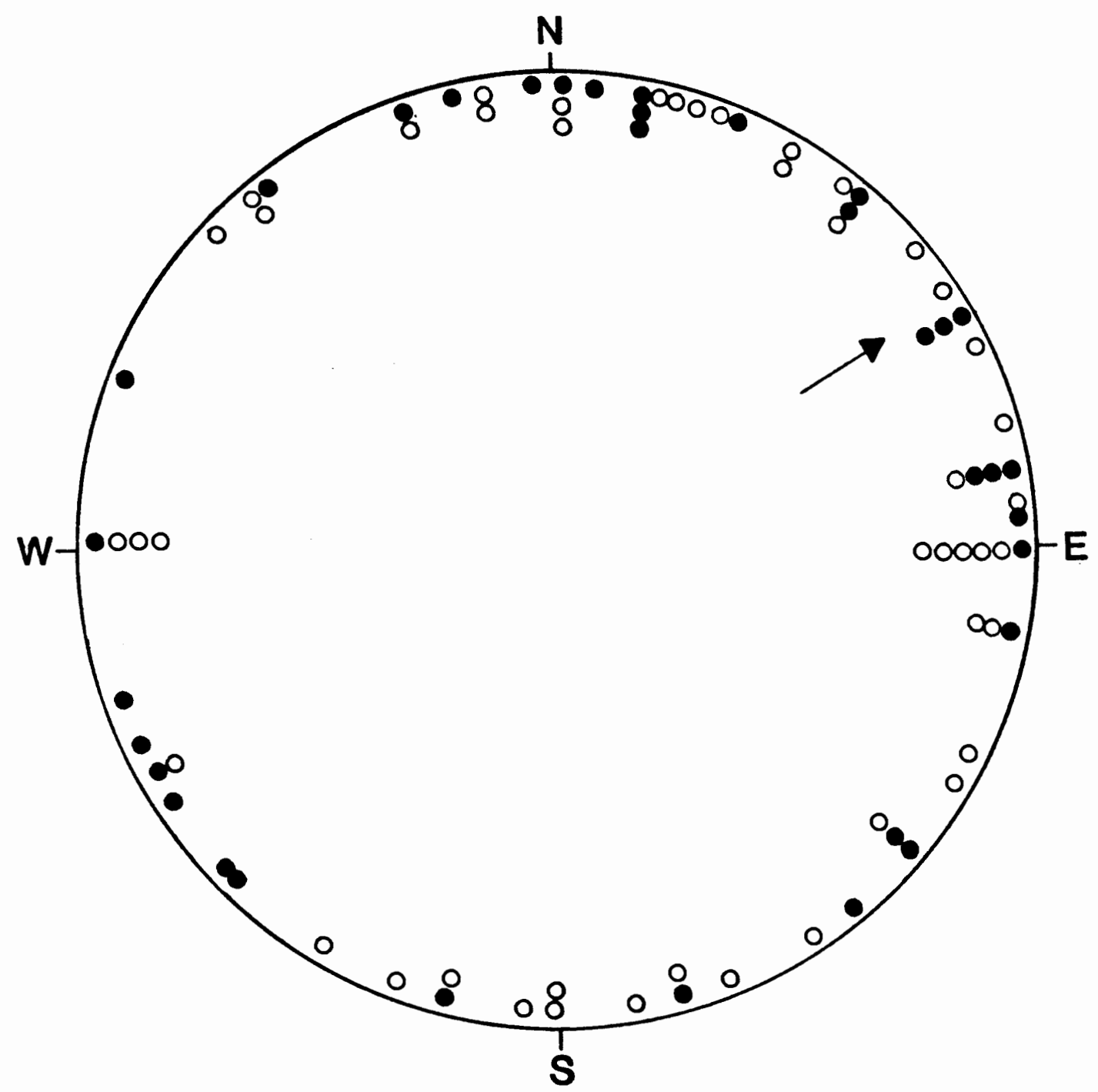

Figure 5. Compass orientation of nest box entrance holes on Parrett Mountain, 1979. Filled circles represent boxes where Western Bluebird nest attempts were made. Mean entrance direction is indicated by the arrow. 


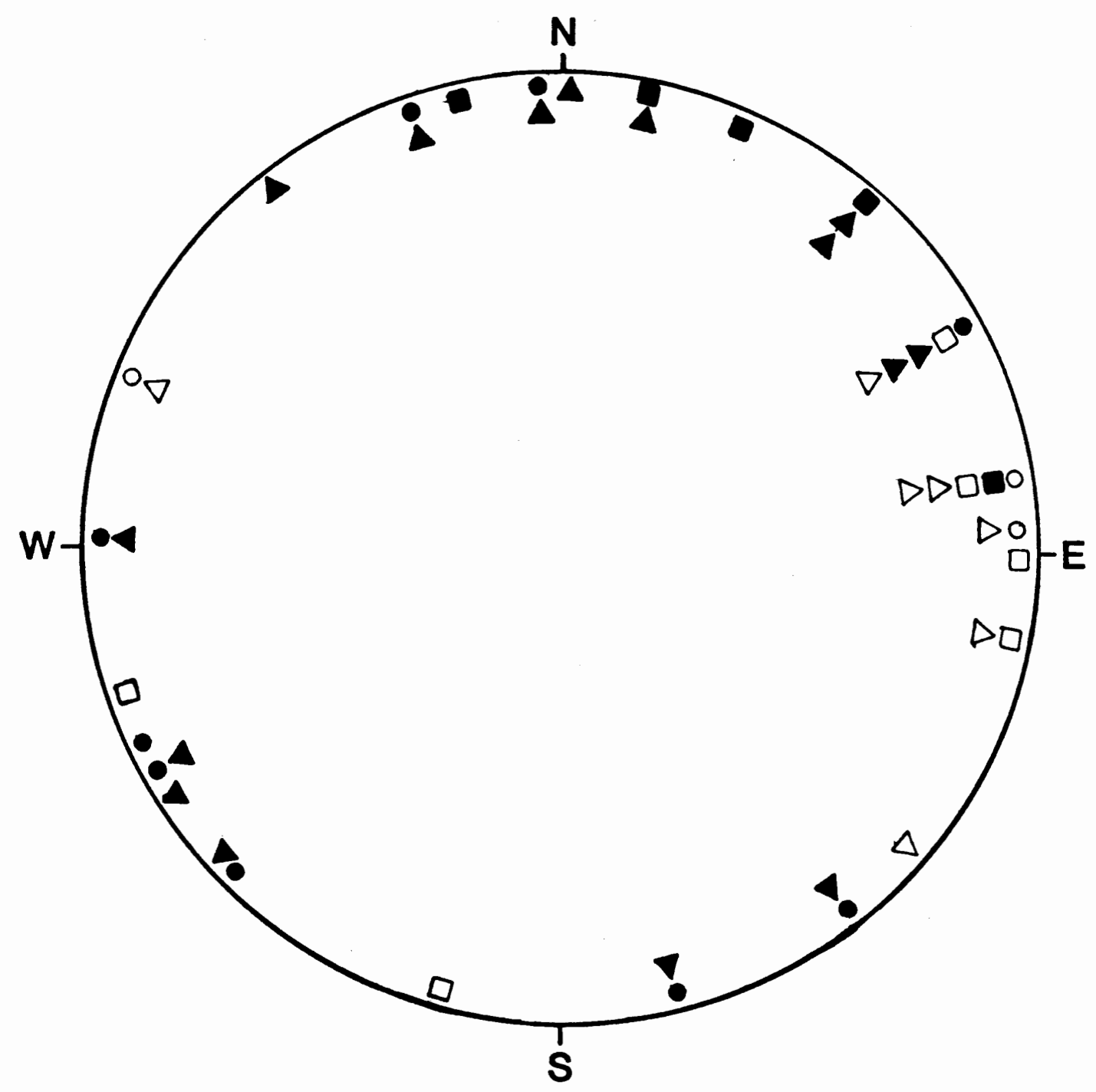

Figure 6. Compass orientation and timing of Western Bluebird nest attempts on Parrett Mountain, 1979. Symbols represent breeding period based on first egg date: circle = spring, square = intermediate, triangle $=$ summer. Filled symbols indicate boxes with solar index less than 0.5 . 
box. Because of the small sample size, no statistical analysis was done.

\section{Solar Index}

Forty of the nest boxes had a solar radiation index of 0.50 or lower; i.e. the boxes were located in the shade (Table IX). Western Bluebird nest box selection and the solar index were tested for association using a $2 \times 2$ contingency table with Yates' correction and found to be significant $\left(x^{2}=6.19, p<0.025,1 \mathrm{df}\right)$. The Western Bluebirds preferred to use boxes mounted in the shade. There was no correlation seen between the number of successful nests and the solar index.

\section{Nest Box Density Index}

Thirty nest boxes were located more than $125 \mathrm{~m}$ from another nest box. Thirty-two boxes were less than $125 \mathrm{~m}$ from another box. In 16 cases, 3 nest boxes were located within a circle with a radius of $125 \mathrm{~m}$. In 1 instance, 4 boxes were within the circle; in another 5 boxes were found. Nest box density, when tested for association with nest box use, was significant $\left(X^{2}=11.05, p<0.005,2 \mathrm{df}\right)$. Western Bluebirds used disproportionately more boxes that had no near neighbors (Table IX). There was no relationship seen between successful bluebird nests and the nest box density index. 
Nest Site Characteristics And Mortality

Nest boxes in which Western Bluebird nest mortalities occurred were divided into groups according to the cause of the mortality. Four nest site characteristics were examined for each sample of boxes. Table $X$ shows the mean entrance height, solar index, nest box density index, and the per cent of boxes mounted on trees found for each group. These are compared to the means given for 35 boxes which contained successful nests; i.e., they fledged at least 1 bluebird. An analysis of variance showed no significance.

Table XI compares the occurrence of bluebird nest mortalities with the time of year and location of nest boxes on trees or fence posts. There were 16 bluebird mortalities which occurred in boxes mounted on trees, and 8 occurred in boxes mounted on fence posts. Due to the small sample size, no statistical analysis was made.

Nest Box Temperatures

Mounting structure, nest box entrance orientation, and solar radiation index are given in Table XII for the 11 boxes used in the temperature studies. The mean temperature change, or the average of the difference between the nest box and ambient temperatures recorded each hour, is listed.

Nest boxes $\mathrm{A}$ and $\mathrm{D}$ ( 30 June) and $\mathrm{K}$ demonstrate the effect that an active Western Bluebird nest has on inside box temperatures. Box A contained bluebird eggs which were being brooded, box $\mathrm{D}$ held naked nestlings, and box $\mathrm{K}$ 
TABLE $\mathrm{X}$

COMPARISON OF MEAN NEST SITE CHARACTERISTICS FOR INDIVIDUAL AND WHOLE-NEST SOURCES OF MORTALITY FOR WESTERN

BLUEBIRDS ON PARRETT MOUNTAIN, 1979

\begin{tabular}{|c|c|c|c|c|c|}
\hline \multirow[b]{2}{*}{ Cause of Mortality } & \multicolumn{2}{|r|}{ Mean Nest } & \multicolumn{2}{|c|}{ Site Characteristic } & \multirow{2}{*}{$\frac{S(\bar{x} \pm S D)}{\begin{array}{c}\text { Tree } \\
\text { Mounting }\end{array}}$} \\
\hline & $\mathrm{n}$ & $\begin{array}{l}\text { Entrance } \\
\text { Height m }\end{array}$ & $\begin{array}{l}\text { Solar } \\
\text { Index }\end{array}$ & $\begin{array}{l}\text { Nest Box } \\
\text { Density }\end{array}$ & \\
\hline $\begin{array}{l}\text { Whole-nest: } \\
\text { Abandoned Eggs } \\
\text { Nestling Death } \\
\text { Nest Failure }\end{array}$ & $\begin{array}{l}4 \\
6 \\
4\end{array}$ & $\begin{array}{l}1.78 \pm .17 \\
1.86 \pm .15 \\
1.84 \pm .23\end{array}$ & $\begin{array}{l}.28 \pm .48 \\
.31 \pm \cdot 36 \\
.44 \pm .27\end{array}$ & $\begin{array}{l}1 \cdot 8 \pm 1 \cdot 0 \\
1 \cdot 7 \pm 0 \cdot 5 \\
1 \cdot 3 \pm 0 \cdot 5\end{array}$ & $\begin{array}{r}75 \% \\
83 \% \\
100 \%\end{array}$ \\
\hline $\begin{array}{l}\text { Individua } 1: \\
\text { Eggs/Nestlings Lost } \\
\text { Nestlings Lost }\end{array}$ & $\begin{array}{l}4 \\
6\end{array}$ & $\begin{array}{l}1.96 \pm .12 \\
1.92 \pm .17\end{array}$ & $\begin{array}{l}.35 \pm .44 \\
.84 \pm .35\end{array}$ & $\begin{array}{l}1.0 \pm 0.0 \\
2.0 \pm 0.9\end{array}$ & $\begin{array}{l}75 \% \\
17 \%\end{array}$ \\
\hline Successful Nests & 35 & $1.89 \pm .20$ & $.45 \pm .44$ & $1.5 \pm 0.7$ & $60 \%$ \\
\hline
\end{tabular}


WESTERN BLUEBIRD INDIVIDUAL AND WHOLE-NEST MORTALITY

RELATED TO NEST BOX LOCATION ON

PARRETT MOUNTAIN, 1979

\begin{tabular}{lcc}
\hline & Mortality* for Boxes & Mounted on \\
\cline { 2 - 3 } Date of First Egg & Trees & Posts \\
\hline Spring & 3 & 1 \\
Intermediate & 9 & 2 \\
Summer & 16 & 5 \\
\hline Totals & 24 & 8 \\
Boxes Used by Bluebirds & 47 & 10 \\
Nest Boxes Available & 33 \\
\hline
\end{tabular}

* Figures do not include unhatched eggs or nestlings death-in-nest. 

ENTRANCE ORIENTATION, SOLAR INDEX, AND MEAN
NEST BOX TEMPERTURE CHANGE FOR
PARRETT MOUNTAIN, 1979

\begin{tabular}{|c|c|c|c|c|c|c|c|}
\hline \multirow[b]{2}{*}{ Box } & \multirow[b]{2}{*}{ Mount } & \multirow[b]{2}{*}{ Compass } & \multirow[b]{2}{*}{ S.I. } & \multicolumn{4}{|c|}{$\begin{array}{l}\text { Mean Temperature Change } \\
(\mathrm{x}+\mathrm{SD}) \text { OC per Hour }\end{array}$} \\
\hline & & & & $\begin{array}{l}\text { rain } \\
30 \text { JUN }\end{array}$ & 20 sun & 6 AUn & $\begin{array}{l}\text { sun } \\
16 \text { AUG }\end{array}$ \\
\hline $\begin{array}{l}\text { A } \\
\text { B } \\
\text { C } \\
\text { D } \\
\text { E }\end{array}$ & $\begin{array}{l}\text { Tree } \\
\text { Tree } \\
\text { Fence } \\
\text { Fence } \\
\text { Tree }\end{array}$ & $\begin{array}{c}110 \\
181 \\
195 \\
195 \\
13\end{array}$ & $\begin{array}{l}0.00 \\
0.25 \\
1.00 \\
1.00 \\
0.10\end{array}$ & $\begin{array}{l}2.6 \pm 3.5 \\
0.4 \pm 0.3 \\
0.3 \pm 0.3 \\
5.8 \pm 1.1 \\
0.7 \pm 0.2\end{array}$ & $\begin{array}{l}0.7 \pm 0.3 \\
0.9 \pm 0.6 \\
1.8 \pm 1.2 \\
1.4 \pm 0.5 \\
0.8 \pm 0.8\end{array}$ & $\begin{array}{l}- \\
\overline{-} \\
\overline{-}\end{array}$ & $\begin{array}{l}\bar{z} \\
\bar{z} \\
\overline{-}\end{array}$ \\
\hline $\begin{array}{l}F \\
G\end{array}$ & $\begin{array}{l}\text { Tree } \\
\text { Tree }\end{array}$ & $\begin{array}{r}11 \\
196\end{array}$ & $\begin{array}{l}0.82 \\
0.82\end{array}$ & - & - & - & - \\
\hline $\begin{array}{l}\mathrm{H} \\
\mathrm{I} \\
\mathrm{J}\end{array}$ & $\begin{array}{l}\text { Tree } \\
\text { Fence } \\
\text { Fence }\end{array}$ & $\begin{array}{r}20 \\
20 \\
200\end{array}$ & $\begin{array}{l}0.14 \\
1.00 \\
1.00\end{array}$ & - & $\begin{array}{l}- \\
-\end{array}$ & $\begin{array}{l}1.7 \pm 0.5 \\
0.6 \pm 0.1 \\
0.8 \pm 0.4\end{array}$ & $\begin{array}{l}1.8 \pm 1.6 \\
1.0 \pm 1.0 \\
1.2 \pm 0.9\end{array}$ \\
\hline $\mathrm{K}$ & Post & 81 & 1.00 & - & - & - & $0.9 \pm 1.1$ \\
\hline
\end{tabular}


contained well feathered young.

Figures 7-10 are graphs of maximum ambient and inside nest box temperatures recorded at the different sites. Nest boxes that were located in the sun - i.e. had solar indices greater than 0.5 - had inside temperatures equal to or greater than ambient temperatures regardless of their entrance orientation. Nest boxes located in the shade were cooler than the surrounding ambient temperatures except for box E. South-facing boxes were not always warmer than north-facing boxes. The temperatures inside 3 nest boxes exceeded $40^{\circ} \mathrm{C}$ on several occasions.

\section{DISCUSSION}

Nest cavities protect birds from harsh weather conditions. Nest placement and entrance orientation may influence the microclimate of the nest and therefore its success. The factors which control nest placement and orientation are largely unknown.

\section{Entrance Orientation}

Studies of primary cavity nesters (Conner 1975, Crockett and Hadow 1975, Inouye 1976, and Inouye et al 1981) indicated that entrance orientation was nonrandom. Cactus Wren (Campylorhynchus brunneicapillus) nest entrance orientation was found to be season specific (Ricklefs and Hainsworth 1969, Austin 1974). Screech owls (Otus asio), which are secondary cavity nesters, used nest boxes facing 


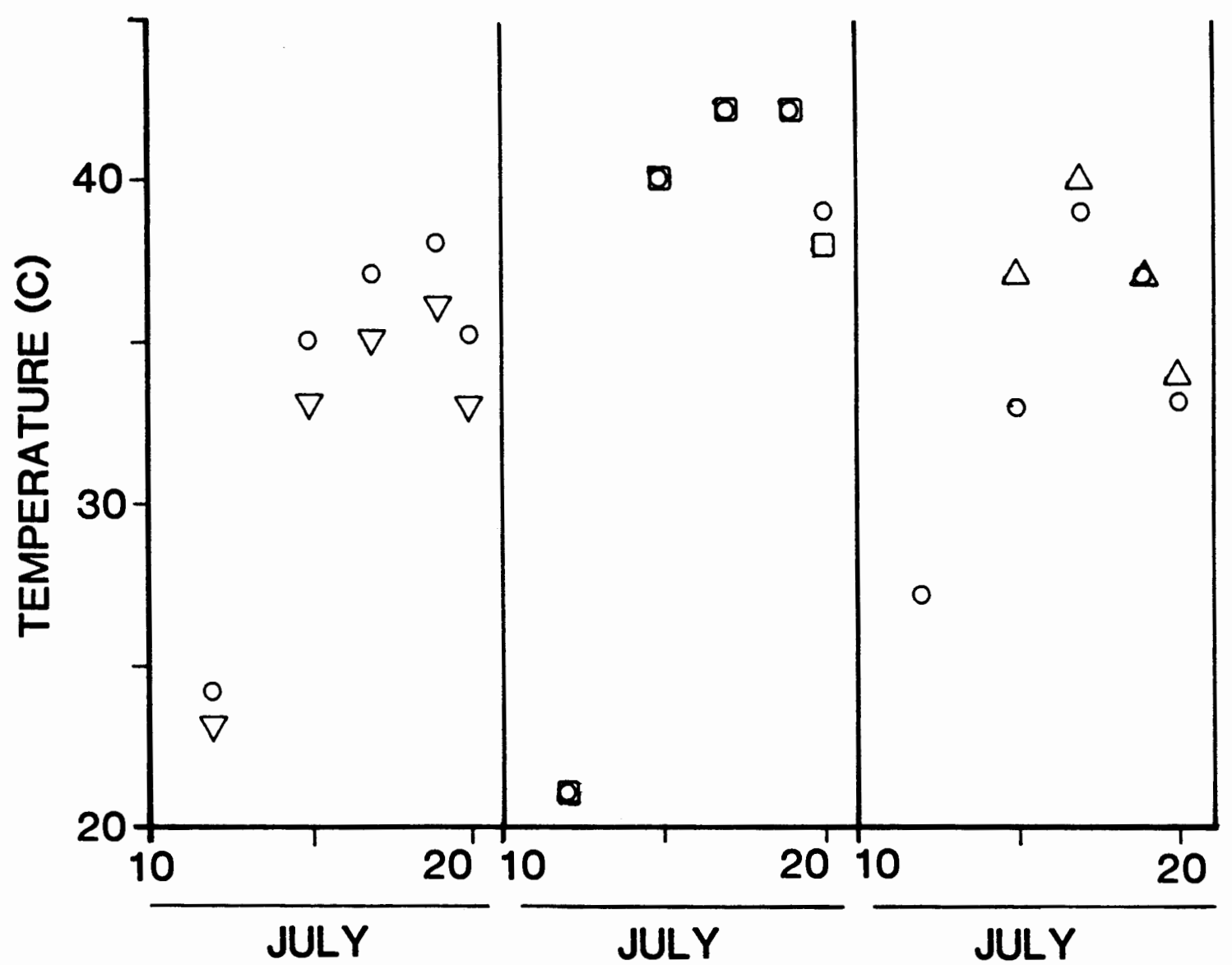

Figure 7. Variation in maximum ambient and nest box temperatures at Site 1 on Parrett Mountain, 1979: circle = ambient, inverted triangle = box $\mathrm{B}$, square = box C, triangle = box E. 


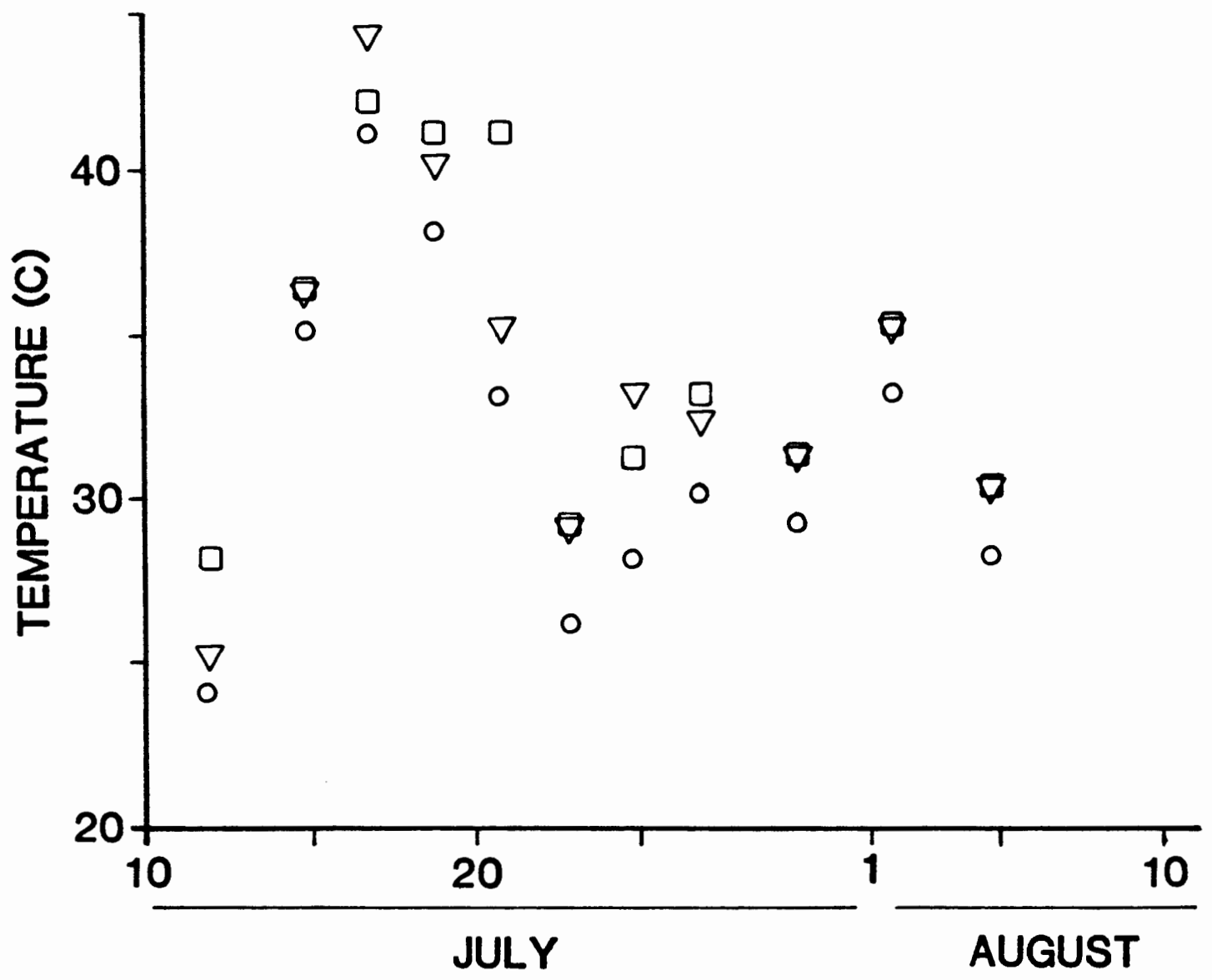

Figure 8. Influence of orientation on maximum nest box temperatures at Site 2 on Parrett Mountain, 1979: circle = ambient, inverted triangle $=$ box $F$, square $=$ box $G$. 


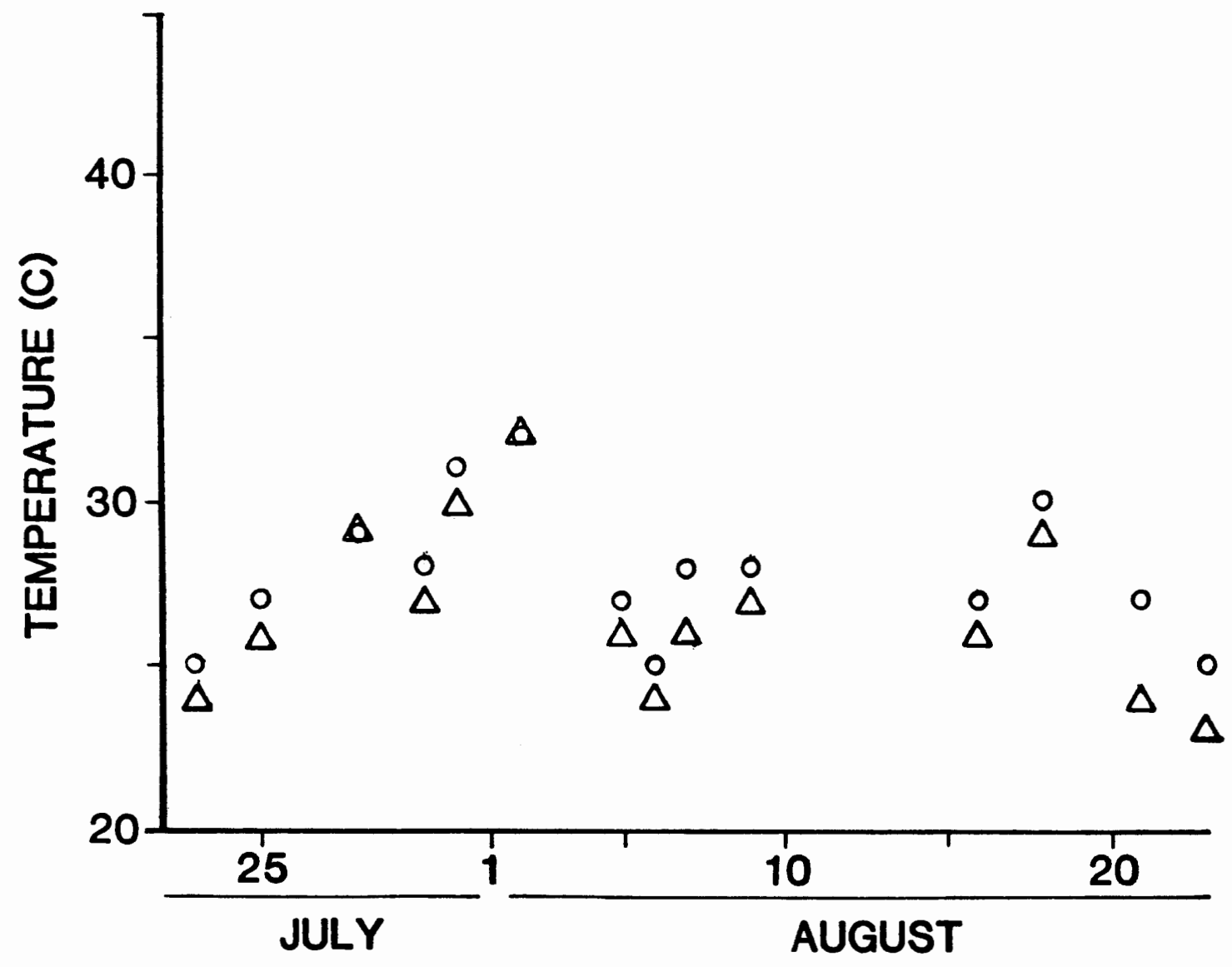

Figure 9. Influence of shading on maximum nest box temperatures at Site 3 on Parrett Mountain, 1979: circle = ambient, triangle $=$ box $\mathrm{H}$. 


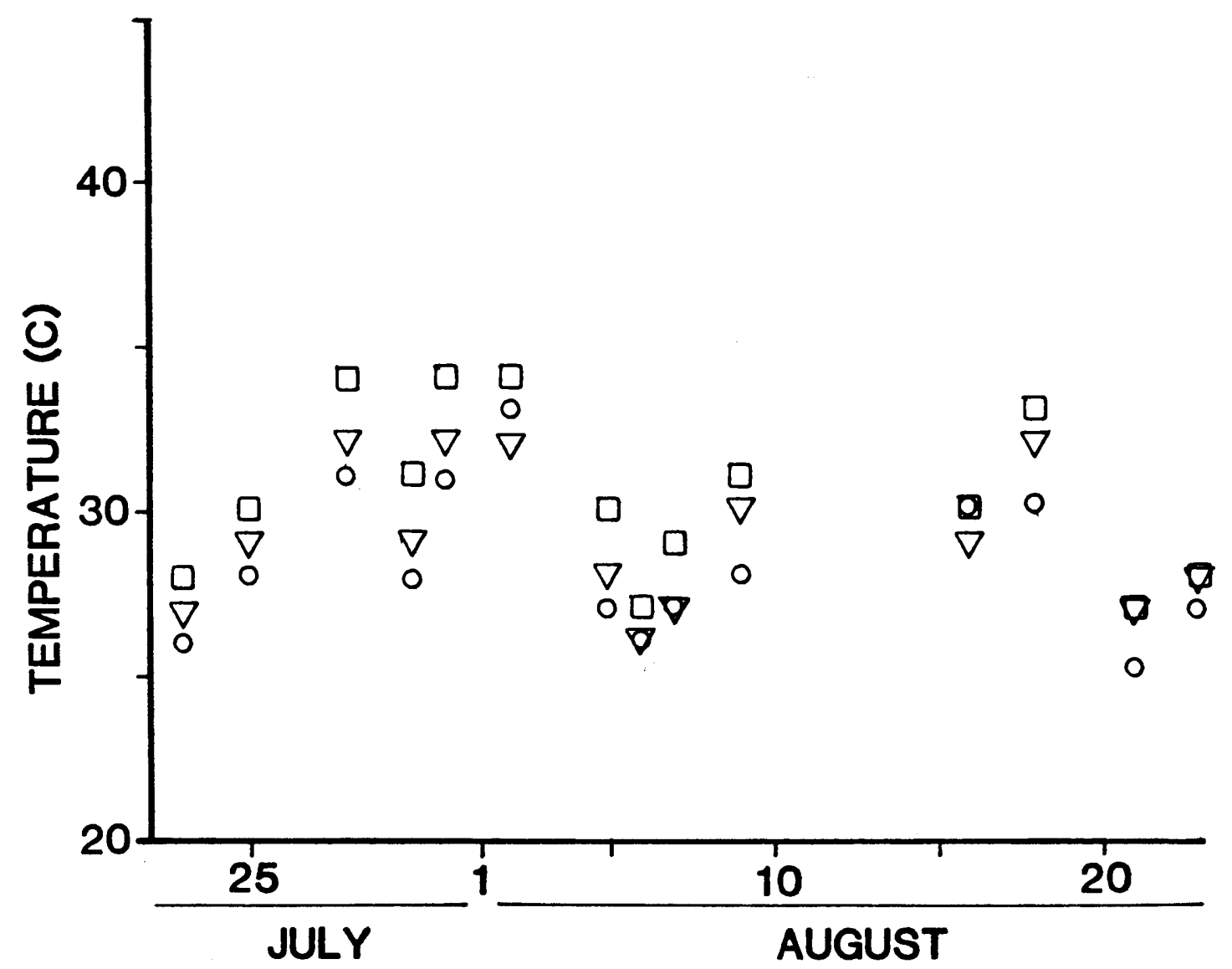

Figure 10. Influence of orientation on maximum nest box temperatures at Site 3 on Parrett Mountain, 1979: circle = ambient, inverted triangle = box $\mathrm{I}$, square $=$ box $\mathrm{J}$. 
north and east out of proportion to their availability (McComb and Noble 1981b). Eastern Bluebirds chose significantly more natural cavities facing southeast (Pinkowski 1976), which may have represented a random selection of available woodpecker nest sites.

The effects of incident solar radiation, ventilation, or rainfall on the nest cavity have been suggested as reasons for preferential entrance orientation. Western Bluebirds on Parrett Mountain, however, selected nest boxes for use in a random manner with respect to entrance orientation. No correlation was found between bluebird nest success and the compass direction of the entrance. This evidence suggests that on Parrett Mountain either the microclimate of the nest box is not significantly influenced by the entrance orientation, or different orientations provide no advantage to the nesting bluebirds.

\section{Solar Index}

Western Bluebirds selected more boxes located in the shade for use in 1979. The amount of shading apparently did not directly affect the number of young fledged as no correlation was seen between nest success and the solar index. The degree to which shading influences the temperature within a nest box is discussed under Nest Box Temperatures. 
Nest Box Density Index

The land surrounding a nest box is important. Bluebird pairs, although able to fly long distances, customarily forage within sight of their box. An area around a box with a poor insect supply results in less food for the nestlings, and the adults may be away from the nest for long amounts of time. The distance between bluebird nests is in part determined by the ability of the land to provide food and perches, and the degree of intraspecific competition experienced. These factors should therefore be reflected in the nest box density index.

On Parrett Mountain in 1979, bluebirds used more boxes that had no near neighbors. This supports the belief that Western Bluebirds do maintain specific territories. There was no relationship seen between nest success and nest box density. Higher concentrations of nest boxes could be used to determine the maximum number of bluebirds that would nest in an area.

Nest Site Characteristics And Mortality

A correlation between the occurrence of nest mortality, specifically the disappearance of 1 or more eggs/nestlings from a nest box, and the mounting of boxes on trees was expected. Presumably predators would find it easier to reach nests in boxes mounted on trees. A very small sample size was available for statistical analysis, and no correlation was found. 
Several cases of apparent nest predation were noted. However, no acts of nest predation were observed, nor were potential predators noticed near boxes. Indications of predation by raccoons itorn apart nests and claw marks on boxes) were not seen. Many of the mortalities did occur in nest boxes that were mounted on trees. In several instances, adult bluebird feathers were found on the tree or nearby on the ground. In these nests the eggs had been destroyed, or the nestlings were dead, dying, or had disappeared. Some nests contained all dead nestlings or the nestlings were missing, but the nest itself was not disturbed. The rear foot and tail of a long-tailed weasel (Mustela frenata) were found near a box where 3 separate incidents of possible nest predation had occurred. The orchard where a second brood died in the nest was littered with groups of plucked feathers from several bird species.

Nest Box Temperatures

Cold, wet weather is known to inhibit foraging by adults, result in abandoned nests, or cause death (Criddle 1927, Weld 1932, Musselman 1939, Haecher 1948, Miller 1970, Scott and Lane 1974). Extreme heat may be fatal to developing Eastern Bluebird embryos and can severly stress young nestlings, thus resulting in lowered nest success (Musselman 1935, Laskey 1940, Thomas 1946, White and Woolfenden 1973). In the field, there are great variations in nest box temperatures due to daily changes in air 
temperature and insolation. Norman and Riggert (1977) found that maximum temperatures inside nest boxes were consistently above ambient. McComb and Noble (1981a) noted that the mean hourly temperature inside nest boxes averaged $0.6^{\circ} \mathrm{C}$ above ambient.

The design and materials used to construct nest boxes will in part determine internal temperatures. Based on research by Huggins (1941) and Kendeigh (1963), Zeleny (1968) suggested that Eastern Bluebird eggs and young nestlings probably could not tolerate temperatures much over $42^{\circ} \mathrm{C}$. Therefore, nest boxes that became warmer than this during the breeding season could be lethal. Zeleny's tests to determine the temperature changes for different box designs being used on bluebird trails showed that wood thickness of $1.9 \mathrm{~cm}$ or more resulted in lower inside temperatures, while the interiors of plastic boxes approached or exceeded lethal limits. A very thick roof did not reduce heat gain significantly. Light external colors kept internal temperatures lower on hot days, while boxes with dark exteriors became twice as warm. The amount of ventilation provided by a "standard" bluebird nest box design reduced inside temperatures, but larger openings were of no advantage. Nest boxes facing the cardinal points showed no significant differences in interior temperatures. A variety of boxes made of unfinished wood had temperature differences of less than $4^{\circ} \mathrm{C}$ (Patterson 1980). 
In areas where periods of extreme heat occur during the breeding season, nest boxes located in the sun or made of less than optimum materials may experience inside temperatures above $42^{\circ} \mathrm{C}$. On Parrett Mountain, Western Bluebirds selected more nest boxes located in the shade. Nest boxes that were in the sun were found to have inside temperatures equal to or greater than ambient temperatures. Temperatures within several boxes being monitered rose to $42^{\circ} \mathrm{C}$ or higher during July.

According to data from the National Climatic Center, 17 July was the hottest day of 1979 for the study area. Young nestlings observed in the late afternoon on $17 \mathrm{July}$ were panting heavily. Panting is a well developed response in nestlings of all ages to elevated temperatures (Ricklefs and Hainsworth 1968). Open mouth breathing occurs at $40-44^{\circ}$ $C$, the breathing rate increases, and older nestlings hold their wings away from their bodies. No mortalities on Parrett Mountain could be directly attributed to this period of high temperatures. Herlugson (1980) also found that Western and Mountain Bluebirds hatching and fledging success did not follow any pattern which could be related to temperature or precipitation. The relatively mild climate of the Portland area during the breeding season, coupled with the data from this study, suggests that nest box temperatures do not significantly affect nest success on Parrett Mountain. 
CONCLUSIONS

Weather, parasites, nest-site competition, habitat destruction, and reduced numbers of nest sites have been cited as possible causes of the alleged decline in Western Bluebird population numbers since the 1940's.

Western Bluebird nest success on Parrett Mountain compares favorably with other Western Bluebird nest box trail results, and with figures for cavity-nesting species in general.

The Western Bluebirds studied showed no nest site preferences with regard to nest box location, mounting structure, entrance height and orientation, or distance to buildings or clusters of trees. They preferred to nest in boxes that were not in close proximity with other bluebird nests.

Temperatures inside nest boxes can exceed $42^{\circ} \mathrm{C}$ during the summer on Parrett Mountain. The internal temperatures of nest boxes located in the sun are equal to or greater than ambient. Western Bluebirds preferred to use boxes located in the shade. No relationship between the microclimate or environment of the nest box and Western Bluebird nest success was found.

The data do not support the contention that nest site availability is a limiting factor on Parrett Mountain. 
There is no direct evidence that the number of suitable nest sites for Western Bluebirds was limited, nor was there any direct evidence of competition with swallows for nest boxes. The sample used for analysis in this study was small, and only 1 season of nesting activites was represented. Many of the results of this study are therefore inconclusive. Data obtained from nest box projects may not be comparable to data derived from studies on the use of natural cavities. Also, because the habitat on Parrett Mountain was considerably modified by man, the statistics generated on Western Bluebird nest success may not be representative for the species as a whole. Therefore it is not possible to draw any definite conclusions concerning the cause of the alleged Western Bluebird population decline from this study. The highly specialized nesting requirements of Sialia mexicana may have resulted in decreased population numbers during recent decades as a variety of environmental changes occurred in the Western states. 
APPENDIX A

WESTERN BLUEBIRD NEST RECORD CARD ANALYSIS

The following method for determining the clutch completion date, clutch size, and the fledging date was based on a computer procedure described by Peakall (1970) and a paper by White and Woolfenden (1973).

\section{Nesting Cycle}

The stage of the nesting cycle at the first visit to the nest box was determined: a)empty; b)incomplete nest; c) completed nest; d)incomplete clutch; e)completed clutch, female brooding; fleggs only, no further information available; gleggs and nestlings; h)nestlings; ilactive but contents unknown; or $j$ )deserted.

Clutch Completion Date. The most probable clutch completion date was calculated by matching the available data with 1 of the following:

1. If the number of eggs increased with successive visits to the nest, then it was assumed that 1 egg was laid per day, and the date of clutch completion was calculated.

2. For a nest with both eggs and nestlings, if at least 1 egg subsequently hatched, the length of the incubation period ( 14 days) was subtracted from the date shown on the card when both eggs and nestlings were present 
(the hatching day).

3. If the record showed only a single date with eggs in the nest, and there were no further data indicating the subsequent number of nestlings, then one-half of the incubation period was subtracted from the date shown to arrive at the date of clutch completion.

4. If several dates were recorded showing the nest contained eggs but no nestlings, and no further information was available, then one-half the incubation period was subtracted from the average of the dates shown.

5. If the approximate age of the nestlings was recorded on several visits, then the most probable date of hatching was first calculated by counting backwards. The length of the incubation period was then subtracted from this date to arrive at the clutch completion date.

6. If no information on the average age of the nestlings was given, then the average date of those recorded was calculated. One-half of the 20 day nestling period and the length of the incubation period were then subtracted from this.

Clutch Size. Clutch size for each nest record was determined as follows:

1. A sufficient number of days must have passed between 2 visits so that an incomplete clutch became a completed clutch.

2. If 2 visits made on different days showed no 
change in the number of eggs, then this was assumed to be the clutch size. For clutches with 4 eggs or less, the data were accepted only if evidence showed that incubation had begun.

3. If only 1 visit to a nest with eggs was made, the number of eggs recorded was used as the clutch size only when on a subsequent visit within the normal incubation period, the number of nestlings in the nest was noted. 4. For nests seen only after hatching, an assumed clutch size was determined based on the number of nestlings and infertile eggs present. These nests were not used in the breeding biology calculations.

Fledging Date. The most probable date that the nestlings left the nest was calculated in the following manner:

1. When 2 or more nestlings were observed leaving the nest box, this was assumed to be the day of fledging.

2. The length of a normal nestling period was added to the hatching date (Day 0). Day 20 was the expected fledging date. If Day 20 fell between 2 visits, where nestlings were present on the first visit and gone on the second, then Day 20 became the fledging date.

3. If the record showed nestlings in the nest on Day 20, then each following visit was examined until a date was found when the box was empty and without signs of mishap or predation. This became the fledging date. 
It was assumed that all the young were present in the nest during the last few days before fledging and left successfully unless physical evidence was seen to the contrary or examination of the empty nest showed signs of disturbance or predation. No fledgings of 17-day old nestlings were observed, so the disappearance of young before this age was believed to be indicative of mortality.

The accuracy of these procedures depends greatly on the stage of the nesting cycle that the nest was found in, and on the number of subsequent visits to the nest and the intervals between these visits.

Sources of Mortality

Each incident of mortality was placed into 1 of the following categories (Caccamise 1978):

Nest Failure - nests found with bluebird egg chips or a dead nestling and some signs of disturbance, where the exact nesting stage and cause of failure were unknown.

Abandoned Eggs - incomplete and complete clutches which were deserted, possibly due to egg predation, nest disturbance, or death of an adult.

Unhatched Eggs - included both embryo mortality and infertility and was detected when 1 or more eggs remained unhatched beyond the normal incubation period.

Eggs/Nestlings Lost At Hatching - otherwise unaccountable single losses of eggs or nestlings during the 2 day hatching period that occurred without obvious changes 
in the physical condition of the nest.

Nestling Death-In-Nest - cases in which 1 or more nestlings were found dead in the nest while the remaining brood members and the nest appeared normal, i.e. death due to starvation.

Nestlings Lost - 1 or more nestlings, 3-17 days old, disappeared from an otherwise successful nest due to predation or accidental nestling eviction.

Nestling Death - loss of all nestlings, generally on a single day, often with signs of nest disturbance, predation, or possible death of the adult.

\section{Causes of Nest Failure}

The following are possible causes of whole-nest mortality (Best and Stauffer 1980): a)predation by birds, snakes, or small mammals - the nest showed no sign of disturbance, but the contents were removed; b)predation by large mammals - the nest cup was disturbed or pulled up, parts of nestlings or adults were present, or adult secondary feathers were found near the box; clabandonment; d) natural disasters or adverse weather. 


\section{APPENDIX B}

\section{DETERMINING MAYFIELD'S NEST SUCCESS}

Mayfield's (1961) method for calculating nest success takes into account the actual number of times each nest was observed in the field, and the fact that not all the nests may have been found before incubation began. Nest mortality either by destruction or desertion is a function of time. In most field studies, nests are found at different stages of the nesting cycle, and the outcome of some is unknown. Nest success is typically overestimated because eggs lost or nests destroyed early in the breeding season are not found. The number of observed losses depends on the number of nests in the sample and the amount of time each nest is under observation. Mayfield called the combination of nests and time exposure. Exposure is measured with the nest-day or 1 nest for 1 day. The total exposure of a group of nests is the summation of all the days spanned by observation at each nest. A nest observed once and then 4 days later represents an observed exposure of 4 nest-days. This is equivalent to the exposure of 2 nests for 2 days each.

Al1 the Western Bluebird nest data were entered on a worksheet and edited according to Mayfield's (1975) criteria. Each nest attempt was given a separate line. 
Nests seen only once were not counted. A nest lost during an interval of several days was arbitrarily assumed to have been lost on the middle day of the interval. Nest-days were counted from the day incubation began (Day 0 ) to the hatching day (the last day). For nests found after incubation had begun, the first day of observation was counted as Day 0 . The number of nest-days for a nesting attempt times the number of eggs in the clutch gave the number of egg-days. Nest-days for nests with young were counted with the hatching day or the first day of observation as Day 0 .

Nests were considered successful if the nestlings were scheduled to fledge during an interval between visits, and if, on the later visit the nest was found empty with no evidence of disturbance. Fledging was assumed to have occurred on the day at the middle of the interval if the fledging day was unknown. The number of nestling-days was equal to the number of nest-days calculated after hatching multiplied by the number of nestlings. If a nestling was lost some time during the nestling period, then the total number of nestling-days was figured in 2 parts based on the changing number of young present in the nest. Mortality is assumed to be approximately even across each stage of the nesting cycle.

The first half of Mayfield's nest success calculation deals with whole nest losses. The probability of survival 
of nests with a mortality rate $r$ for a period of days $d$ is $(1-r)^{d}$. The survival rate $S$ equals $1-r$, so the probability of survival is $\mathrm{s}^{\mathrm{d}}$.

During incubation, 31 Western Bluebird nests were seen which represents a total exposure of 389 nest-days. Three nests were lost. The mortality rate is $3 / 389=.008$ nests lost per nest-day during incubation. The probability of nest survival of the incubation period then is $.992^{14}=.89$ for an average incubation period of 14 days. This means that 100 nests at the start of incubation would be expected to decline to 89 nests at hatching.

Forty nests were observed during the nestling period with a total exposure of 578 nest-days. Six nests were lost. Therefore, the mortality rate is $6 / 578=.010$ nests per day. The survival rate $(1-r)$ is .99 . The probability of nest survival for an average nestling period of 20 days is $.99^{20}=.82$.

The probability that Western Bluebird nests will survive both the incubation and the nestling periods is just the product of the separate probabilities or $.89 \times .82=$ .73 .

Next, individual losses of eggs or nestlings are examined for each stage of the nesting cycle. No individual eggs were lost from the 31 nests observed during the incubation period without the loss of all the eggs in the clutch. There were 2107 total egg-days. With no mortality 
per egg-day, there was $100 \%$ survival of the individual eggs. The probability of nest survival (.89) times the probability that eggs will survive individual losses (1.00) equals the probability of egg survival during incubation (.89). In this study, egg survival is therefore equivalent to nest survival during incubation.

Nestling survival during the hatchling period represents the hatching success of eggs present at hatching time, plus the individual survival of nestlings during the first few hours of life. The hatching period was defined by Mayfield as the 2 days following the hatching of the first egg in a nest. At hatching time 181 eggs were present, and 158 nestlings were present 2 days later. The probability of survival of the hatching period is $158 / 181=.87$.

The probability of nestlings surviving from the second day after hatching until fledging is determined next. During the nestling period 40 nests were observed, and 16 individual nestlings were lost from nests which went on to fledge at least 1 young. With a total of 2572 nestling-days, $16 / 2572$ gives a mortality rate of .006 . The probability that nestlings will survive individual losses is $(.994)^{20}$ or $89 \%$. The probability of nestling survival until fledging is the probability of individual survival (.89) multiplied by the probability of nest survival during the nestling period $(.82)$ to give .73 .

Finally, the probability that an egg present at the 
start of incubation will produce a fledgling is equal to the probability that an egg will survive the incubation period (.89) times the probability that an egg will hatch $(.87)$ times the probability of a nestling surviving to fledging (.73) equals .57. Table XIII is a summary of this information. 
TABLE XIII

MAYFIELD'S SUCCESS OF NESTS AND EGGS/NESTLINGS ACCORDING TO THE STAGE OF THE NESTING CYCLE FOR WESTERN

BLUEBIRDS ON PARRETT MOUNTAIN, 1979

\begin{tabular}{|c|c|c|c|c|c|c|c|c|}
\hline \multicolumn{3}{|c|}{$\begin{array}{c}\text { Incubation }^{1} \\
\text { Period }\end{array}$} & \multirow{2}{*}{$\begin{array}{l}\text { Hatching } \\
\text { Period } \\
\text { nestlings }\end{array}$} & \multicolumn{3}{|c|}{$\begin{array}{l}\text { Nestling } \\
\text { Period }\end{array}$} & \multicolumn{2}{|c|}{$\begin{array}{l}\text { Start of } \\
\text { Incubation } \\
\text { to Fledging }\end{array}$} \\
\hline $\mathrm{n}$ & nests & eggs & & $\mathrm{n}$ & nests & nestlings & nests & $\begin{array}{l}\text { eggs or } \\
\text { nestlings }\end{array}$ \\
\hline 31 & $89 \%$ & $89 \%$ & $87 \%$ & 40 & $82 \%$ & $73 \%$ & $73 \%$ & $57 \%$ \\
\hline
\end{tabular}

1. see text for length of periods

2 . this computation includes hatching success of $87 \%$ 


\section{LITERATURE CITED}

Abbott, C.G. 1927. Western Bluebird nesting in the city of San Diego. Condor 29:165.

Andrews, R.W. and C.E. Block. 1979. A Christmas Bird Count analysis of bluebird abundance patterns and population trends. Sialia $1: 10-14$.

Anonymous. 1971. Announcing the Blue List: an "early warning system" for birds. American Birds 25:948-949.

Antony, A.W. 1886. Field notes on birds of Washington County, Oregon. Auk 3:161-172.

Arnold, J.R. 1937. Birds of the Coaling area, Fresno County, California. Condor 39:31-35.

Arnold, R. and J.R. Femberton. 1916. Nesting of the Western Bluebird at Ventura, California. Condor $18: 86$.

Atkinson, B. 1974. Fewer bluebirds are heralding spring's return. Smithsonian 5:38-45.

Austin, G.T. 1974. Nesting success of the Cactus Wren in relation to nest orientation. Condor 76:216-217.

Bailey, A.M. and R.J. Niedrach. 1965. Birds of Colorado. Denver Museum of Natural History, Denver. 895 p.

Balda, R. 1975. The relationship of secondary cavity nesters to snag densities in western coniferous forests. U.S. Forest Service Wildlife Habitat Technical Bulletin 1, Albuquerque.

Barlow, C. 1901. A list of the land birds of the Placerville-Lake Tahoe stage road. Condor 3:151-184.

Bart, J. 1977. Impact of human visitation on avian nesting success. Living Bird 16:190.

Batschelet, E. 1965. Statistical methods for the analysis of problems in animal orientation and certain biological rhythms. American Institute of Biological Sciences, Washington, D.C. 
Beal, F.E.L. 1915. Food of the robins and bluebirds of the United States. U.S.D.A. Bulletin 171, Washington, D.C. 31 p.

Beebe, S.B. 1974. Relationships between insectivorous hole-nesting birds and forest management. Yale University, New Haven. Unpublished. 49 p.

Bent, A.C. 1949. Life histories of North American thrushes, kinglets, and their allies. U.S. National Museum Bulletin 196, Washington, D.C. 454 p.

Bertrand, G.A. and J.M. Scott. 1979. A checklist of the birds of Oregon, 3rd edition (revised by M.S. Eltzroth and F.L. Ramsey). Oregon State University Bookstore, Corvallis.

Best, L.B. and D.F. Stauffer. 1980. Factors affecting nesting success in riparian bird communities. Condor $82: 149-158$.

Boone, D.D. 1982a. Are Tree Swallows colonial? Sialia $4: 8-9$.

Boone, D.D. 1982b. Managing trails for bluebird-swallow balance. Sialia 4:10-11.

Bowles, J.H. 1906. A list of the birds of Tacoma, Washington, and vicinity. Auk 23:138-148.

Bryan, M. 1901. A study of the birds of Santiago Canyon. Condor 3:103-104.

Bryant, H.C. 1911. The relation of birds to an insect outbreak in northern California during the spring and summer of 1911. Condor 13:195-208.

Burleigh, T.D. 1921. Breeding birds of Warland, Lincoln County, Montana. Auk 38:552-565.

Burleigh, T.D. 1930. Notes on the bird life of northwestern Washington. Auk 47:48-63.

Caccamise, D.F. 1977. Breeding success and nest site characteristics of the Red-winged Blackbird. Wilson Bulletin 89:396-403.

Caccamise, D.F. 1978. Seasonal patterns of nesting mortality in the Red-winged Blackbird. Condor $80: 290-294$.

Carter, F. 1937. Bird life at Twentynine Palms. Condor 
$39: 210-219$.

Chambers, W.L. 1915. Western Bluebird nesting in Los Angeles. Condor 17:235.

Clabaugh, E.D. 1924. Western Bluebird nesting in Berkeley. Condor $26: 228$.

Conner, R.N. 1975. Orientation of entrances to woodpecker nest cavities. Auk 92:371-374.

Cooke, W.W. 1895. The summer range of Colorado birds. Auk $12: 150-155$.

Cowan, I. McT. 1942. Termite-eating by birds in British Columbia. Auk 59:451.

Cowles, R.B. 1933. Minutes of Cooper Club meetings. Condor 35:45.

Criddle, N. 1927. Habits of the Mountain Bluebird in Manitoba. Canadian Field Naturalist 41:40-44.

Crockett, A.B. and H.H. Hadow. 1975. Nest site selection by Williamson and Red-naped Sapsuckers. Condor $77: 365-368$.

Dahlsten, D.L. and W.A. Copper. 1979. The use of nesting boxes to study the biology of the Mountain Chickadee (Parus gambeli) and its impact on selected forest insects. In: Dickson, J.G., R.N. Conner, R.R. Fleet, J.C. Knoll, and J.A. Jackson, ed., The role of insectivorous birds in forest ecosystems. Academic Press, New York. 381 p.

Davis, J. 1957. Comparative foraging behavior of the Spotted and Brown Towhees. Auk 74:129-166.

Dice, L.R. 1918. The birds of Walla Walia and Columbia Counties, southeastern Washington. Auk 35:148-161.

Dixon, J.S. 1943. Birds of the Kings Canyon National Park area of California. Condor 45:205-219.

Drinkwater, H. 1953. Young bluebird being taken from nest-box by Sparrow Hawk (Falco sparverius). Auk $70: 215$.

Edwards, H.A. 1914. Bird notes from the Sierra Madre Mountains, southern California. Condor 16:207-210.

Eltzroth, E.K. 1980. Bluebird Express. Sialia 2:120. 
Eltzroth, E.K. 1981. Incomplete albinism in a Western Bluebird nestling. Oregon Birds 7:134.

E1tzroth, E.K., A.S. Cromack, and L.T. Thompson-Cowley. 1980. Endoparasitism in Western Bluebirds of Oregon. Sialia 2:67-71.

Erskine, A.J. and W.D. McLaren. 1972. Sapsucker nest holes and their use by other species. Canadian Field Naturalist $86: 357-361$.

Erskine, A.J. and W.D. McLaren. 1976. Comparative nesting biology of some hole-nesting birds in the Cariboo Parklands, British Columbia. Wilson Bulletin $88: 611-620$.

Evermann, B.W. 1886. A list of the birds obtained in Ventura County, California. Auk 3:179-186.

Felters, C.H. 1936. Trapping Cedar Waxwings in the San Joaquin Valley, California. Condor 38:18-23.

Finley, W.L. 1907. Two studies in blue. Condor 9:121-127.

Fisher, W.K. 1902. The redwood belt of northwestern California. Condor 4:111-114.

Franzreb, K.E. and R.D. Ohmart. 1978. The effects of timber harvesting on breeding birds in a mixedconiferous forest. Condor 80:431-441.

Gabrielson, I.N. 1924. Notes on the birds of Wallowa County, Oregon. Auk 41:552-565.

Gabrielson, I.N. 1931. The birds of the Rogue River Valley, Oregon. Condor 33:110-121.

Gabrielson, I.N. and S.G. Jewett. 1940. Birds of Oregon. Oregon State College, Corvallis. Reprint: 1970, as Birds of the Pacific Northwest. Dover Pub., Inc. New York. 650 p.

Gander, F.F. 1960. Western Bluebirds in my garden. Audubon 62:70-71, 83.

Gary, H.L. and M.J. Morris. 1980. Constructing wooden boxes for cavity-nesting birds. U.S.D.A. Forest Service Research Note RM-381.

Goldman, E.A. 1908. Summer birds of the Tulare Lake region. Condor 10:200-205. 
Gottfried, B.M. and C.F. Thompson. 1978. Experimental analysis of nest predation in an old-field habitat. Auk 95:304-312.

Green, R.F. 1977. Do more birds produce fewer young? A comment on Mayfield's measure of nest success. Wilson Bulletin $89: 173-175$.

Griffee, W.E. and E.F. Rapraeger. 1937. Nesting dates for birds breeding in the vicinity of Portland, Oregon. Murrelet 18:14-18.

Grinnel1, J. 1904. Midwinter birds at Palm Springs, California. Condor 6:40-45.

Grinnel1, J. 1905. Summer birds of Mount Pinos, California. Auk 22:378-391.

Grinnel1, J. 1911. Distribution of the Mockingbird in California. Auk 28:293-300.

Grinnell, J. and A.H. Miller. 1944. The distribution of the birds of California. Pacific Coast Avifauna 27. $608 \mathrm{p}$.

Guberlet, J.E. and H.H. Hotson. 1940. A fly maggot attacking young birds, with observations of its life history. Murrelet 21:65-68.

Guillion, G.W., W.M. Pulich, and F.G. Evenden. 1959. Notes on the occurrence of birds in southern Nevada. Condor $61: 278-297$.

von Haartman, L. 1957. Adaptation in hole-nesting birds. Evolution 11:339-347.

Haecker, F.W. 1948. A nesting study of the Mountain Bluebird in Wyoming. Condor 50:216-219.

Harris, H. 1919. Notes on some Catalina Island birds. Condor 21:171-172.

Harrison, G. 1978. A field guide to the nests, eggs, and nestlings of North American birds. Collins Pub., New York. 416 p.

Havera, S.P. 1979. Temperature variation in a fox squirrel nest box. Journal of Wildlife Management 43:251-253.

Hays, W.L. 1963. Statistics. Holt, Rinehart and Winston, Inc. New York. 719 p. 
Hering, L. 1948. Nesting birds of the Black Forest, Colorado. Coildor 50:49-56.

Herlugson, C.J. 1978. Comments on the status and distribution of Western and Mountain Bluebirds in Washington. Western Birds 9:21-32.

Herlugson, C.J. 1980. Biology of sympatric populations of Western and Mountain Bluebirds. Ph.D. thesis, Washington State University, Pullman. 133 p.

Herlugson, C.J. 1981. Nest site selection in Mountain Bluebirds. Condor 83:252-255.

Huggins, R.A. 1941. Egg temperatures of wild birds under natural conditions. Ecology 22:148-57.

Ingles, L.G. 1950. Nesting birds of the willow-cottonwood community in California. Auk 67:325-332.

Inouye, D.W. 1976. Nonrandom orientation of entrance holes to woodpecker nests in aspen trees. Condor $78: 101-102$.

Inouye, R.S., N.J. Huntly, and D.W. Inouye. 1981. Nonrandom orientation of Gila Woodpecker nest entrances in Saguaro cacti. Condor 83:88-89.

Jackson, J.A. and J. Tate, Jr. 1974. An analysis of nest box use by Purple Martins, House Sparrows, and Starlings in eastern North America. Wilson Bulletin $86: 435-449$.

Jaeger, E.C. 1949. Relation of the desert ironwood tree to nesting. Auk 66:211-212.

James, D. 1963. The changing seasons. Audubon Field Notes $17: 300-304$.

Jensen, J.K. 1923. Notes on the nesting birds of northern Santa Fe County, New Mexico. Auk 40:452-469.

Jewett, S.G. 1909. Some birds of Baker County, Oregon. Auk 26:5-9.

Jewett, S.G. 1916. Notes on some Iand birds of Tillamock County, Oregon. Condor 18:74-80.

Jewett, S.G. and I.N. Gabrielson. 1929. Birds of the Portland area, Oregon. Pacific Coast Avifauna 19. $54 \mathrm{p}$. 
Jewett, S.G., W.P. Taylor, W.T. Shaw, and J.W. Aldrich. 1953. Birds of Washington State. University of Washington Press, Seattle. 767 p.

Johnson, N.K. 1965. The breeding avifaunas of the Sheep and Spring Ranges in southern Utah. Condor 67:93-124.

Johnston, D.W. 1949. Populations and distribution of summer birds of Latah County, Idaho. Condor $51: 140-149$.

Karlsson, J. and S.G. Nilsson. 1977. The influence of nest-box area on clutch size in some hole-nesting passerines. Ibis 119:207-211.

Kendeigh, S.C. 1961. Energy of birds conserved by roosting in cavities. Wilson Bulletin 73:140-147.

Kendeigh, S.C. 1963. New ways of measuring the incubation period of birds. Auk 80:453-461.

Kibler, L.F. 1969. The establishment and maintenance of a bluebird nest-box project - a review and commentary. Bird Banding 40:114-129.

Klett, A.T. and D.H. Johnson. 1982. Variability in nest survival rates and implications to nesting studies. Auk 99:77-87.

Laskey, A.R. 1939. A study of nesting Eastern Bluebirds. Bird Banding 10:23-32.

Laskey, A.R. 1940. The 1939 nesting season of bluebirds at Nashville, Tennessee. Wilson Bulletin 52:183-190.

Law, J.E. 1929. Down-tree progress of Sitta pygmaea. Condor 31:45-51.

Ligon, J.S. 1961. New Mexico birds and where to find them. University of New Mexico Press, Albuquerque. $360 \mathrm{p}$.

Lowe, W.P. 1894. A list of the birds of the Wet Mountains, Huerfano County, Colorado. Auk 11:266-270.

Lumsden, H.G. 1976. Choice of nest boxes by Starlings. Wilson Bulletin 88:665-666.

Mailliard, J. and J. Grinnel1. 1905. Midwinter birds on the Mojave Desert. Condor 7:71-77, 101-102.

Mansfield, G.S. 1946. Wintering Mountain Bluebirds on the Santa Barbara coast. Condor 48:285. 
Marsha11, D.B. 1978. Familiar birds of Northwest forests, fields, and gardens. Durham and Downey, Inc., Portland. $84 \mathrm{p}$.

Marshall, J.T., Jr. 1957. Birds of pine-oak woodland in southern Arizona and adjacent Mexico. Pacific Coast Avifauna 32. $125 \mathrm{p}$.

Mayfield, H.F. 1961. Nesting success calculated from exposure. Wilson Bulletin 73:225-261.

Mayfield, H.F. 1975. Suggestions for calculating nest success. Wilson Bulletin 87:456-466.

McCluskey, D.C., J.W. Thomas, and E.C. Meslow. 1977. Effects of aerial application of DDT on reproduction in House Wrens and Mountain and Western Bluebirds. U.S.D.A. Forest Service Research Paper PNW-228. 22 p.

McComb, W.C. and R.E. Noble. 1981a. Microclimates of nest boxes and natural cavities in bottomland hardwoods. Journal of Wildlife Management 45:284-289.

McComb, W.C. and R.E. Noble. 1981b. Nest-box and natural cavity use in three mid-south forest habitats. Journal of Wildlife Management 45:93-101.

McKnight, E.T. 1973. A nest box project for bluebirds in Stafford County, Virginia. Raven 44:59-68.

Merriam, F.A. 1896. Notes on some of the birds of southern California. Auk 13:115-124.

Merri11, J.C. 1888. Notes on the birds of Fort Klamath, Oregon. Auk 5:357-366.

Michael, C.W. 1936. New nesting records for Yosemite Valley. Condor 38:85-86.

Miller, A.H. 1951. An analysis of the distribution of the birds of California. University of California Publications of Zoology 50:531-644.

Miller, A.H. and C.E. Bock. 1972. Natural history of the Nuttal1 Woodpecker at the Hastings Reservation. Condor 74:284-294.

Miller, L.H. 1904. The birds of the John Day region, Oregon. Condor 6:100-106.

Miller, W. 1970. Factors influencing the status of Eastern and Mountain Bluebirds in southwestern Manitoba. Blue 
Jay $28: 38-46$.

Mills, G.S. 1976. American Kestrel sex ratios and habitat separation. Auk 93:740-748.

Musselman, T.E. 1934. Help the bluebirds. Bird-Lore $36: 9-13$.

Musselman, T.E. 1935. Three years of Eastern Bluebird banding and study. Bird-Banding 6:117-125.

Musselman, T.E. 1939. The affect of cold snaps upon the nesting of the Eastern Bluebird. Bird-Banding $10: 33-35$.

Myers, H.W. 1912. Nesting habits of the Western Bluebird. Condor 14:221-222.

Nice, M.M. 1941. The role of territory in bird life. American Midland Naturalist 26:441-487.

Nice, M.M. 1957. Nesting success in altricial birds. Auk $74: 305-321$.

Norman, F.I. and T.L. Riggert. 1977. Nest boxes as nest sites for Australian waterfowl. Journal of Wildlife Management 41:643-649.

North American Bluebird Society. 1979. Nesting box record card program. Sialia 1:82-87.

O'Connor, R.J. 1978. Nest-box insulation and the timing of laying in the Wytham woods population of Great Tits Parus major. Ibis 120:534-536.

Packard, F.M. 1945. The birds of Rocky Mountain National Park, Colorado. Auk 62:371-394.

Patterson, R.M. 1980. More on nesting box temperatures. Sialia $2: 15-18$.

Peaka11, D.B. 1970. The Eastern Bluebird: its breeding season, clutch size, and nesting success. Living Bird 9:239-256.

Pederson, R.J. and L.D. Bryant. 1975. Observations on birds in the Blue Mountains. Murrelet 56:7-10.

Phillips, A.R., J.T. Marshal1, Jr., and G. Monson. 1964 . The birds of Arizona. University of Arizona Press, Tucson. $212 \mathrm{p}$. 
Pinkowski, B.C. 1974. A comparative study of the behavioral and breeding ecology of the Eastern Bluebird (Sialia sialis). Ph.D. thesis. Wayne State Univ., Detroit. 471 p.

Pinkowski, B.C. 1975. A summary and key for determining causes of nesting failures in Eastern Bluebirds using nesting boxes. Inland Bird Banding News 47:179-186.

Pinkowski, B.C. 1976. Use of tree cavities by nesting Eastern Bluebirds. Journal of Wildlife Management $40: 556-563$.

Pinkowski, B.C. 1977a. Blowfly parasitism of Eastern Bluebirds in natural and artifical nest sites. Journal of Wildlife Management 41:272-276.

Pinkowski, B.C. 1977b. Breeding adaptations in the Eastern Bluebird. Condor 79:289-302.

Pinkowski, B.C. 1977c. Foraging behavior of the Eastern Bluebird. Wilson Bulletin 89:404-414.

Pinkowski, B.C. 1979a. Foraging ecology and habitat utilization in the genus Sialia. In: Dickson, J.G., R.N. Conner, R.R. Fleet, J.C. Kroll, and J.A. Jackson, ed., The role of insectivorous birds in forest ecosystems. Academic Press, New York. 381 p.

Pinkowski, B.C. 1979b. Nest site selection in Eastern Bluebirds. Condor 81:435-436.

Pitelka, F.A. 1941. Foraging behavior in the Western Bluebird. Condor 43:198-199.

Popper, D.M. 1951. Notes on the birds of Mount Locke, Texas. Condor 53:51-54.

Power, H.W. 1966. Biology of the Mountain Bluebird in Montana. Condor 68:351-371.

Power, H.W. 1980. The foraging behavior of Mountain Bluebirds with emphasis on sexual foraging differences. Ornithological Monographs 28. 72 p.

Prescott, H.W. 1977. Portland bluebird trail - SWOC Talk: An Oregon bird review. Oregon Birds 3:17-35.

Prescott, H.W. 1979. Oregon's Williamette Valley. Sialia $1: 52-54,56,81$.

Prescott, H.W. 1980. Causes of decline of the Western 
Bluebird in Oregon's Willamette Valley. Sialia 2:131-135.

Prescott, H.W. 1982. Using paired nesting boxes to reduce swallow-bluebird competition. Sialia 4:3-7.

Price, W.W. 1899. Some winter birds of the lower Colorado Valley. Condor 1:89-93.

Prigge, A.A. 1978. The bluebird trail project, forth annual report. Nature Trails 12:4-6.

Prigge, A.A. 1979. Bluebird Express. Sialia 1:137.

Prigge, A.A. 1981. Reducing swallow-bluebird competition. Sialia 3:49-50.

Prigge, A.A. 1982. More on reducing swallow-bluebird competition. Sialia $4: 7-8$.

Racey, K. 1926. Notes on the birds observed in the Alta Lake region, British Columbia. Auk 43:319-325.

Racey, K. 1939. Western Bluebird notes. Canadian Field Naturalist $53: 30$.

Racey, K. 1948. Birds of the Alta Lake region, British Columbia. Auk 65:383.

Rathbun, S.R. 1902. A 1ist of the land birds of Seattle, Washington, and vicinity. Auk 19:131-141.

Ray, M.S. 1905. A third trip to the high Sierras. Auk $22: 363-371$.

Ray, M.S. 1912. A journey to the Star Lake County and other notes from the Tahoe region. Condor 14:142-147.

Ray, M.S. 1914. Some discoveries in the forest at Fyffe. Condor 16:57-70.

Ray, M.S. 1918. Six weeks in the high Sierras in nesting time. Condor 20:70-78.

Richardson, G.H., Jr. 1904. A list of summer birds of the Puite Mountains, California. Condor 6:134-137.

Richmond, S.M. 1953. The attraction of Purple Martins to an urban location in western Oregon. Condor $55: 225-249$.

Ricklefs, R.E. and F.R. Hainsworth. 1968. Temperature 
regulation in nestling Cactus Wrens: the development of homeothermy. Condor 70:121-127.

Ricklefs, R.E. and F.R. Hainsworth. 1969. Temperature regulation in nestling Cactus Wrens: the nest environment. Condor 71:32-37.

Ridgway, R. 1894. On geographical variation in Sialia mexicana Swainson. Auk 11:145-160.

Ridgway, R. 1907. The birds of North and Middle America. U.S. National Museum Bulletin 50, Washington, D.C.

Riney, T. 1951. Relationships between birds and deer. Condor 53:178-185.

Robbins, C.S. 1974. Monitoring bird population trends. Timber-Wildlife Management Symposium. Missouri Academy of Science, Occasional Paper 3:96-100.

Rockwell, R.B. and A. Wetmore. 1914. A list of birds from the vicinity of Golden, Colorado. Auk 31:309-333.

Roest, A.I. 1957. Observations on birds of central Oregon. Condor 59:141-142.

Ross, R.C. 1933. Western Bluebird nesting in a wall tile. Condor 35:73-74.

Salomonson, M.G. and R.P. Balda. 1977. Winter territoriality of Townsend's Solitaires (Myadestes townsendi) in a pinon-juniper-ponderosa pine ecotone. Condor 79: 148-161.

Scott, L. and J. Lane. 1974. Mountain Bluebird travels 130 miles to renest. Blue Jay 32:44-45.

Seibert, M.L. 1942. Occurrence and nesting of some birds in the San Francisco Bay regions. Condor 44:68-72.

Shepardson, D.I. 1915. Bluebird nesting in Low County. Condor $17: 206$.

Skutch, A.F. 1961. Helpers among birds. Condor $63: 198-226$.

Sma11, A. 1974. Annotated list of the birds of California. Wirchester Press, New York. 310 p.

Stoner, E.A. 1940. Townsend Solitaire at Benicia, California. Condor 42:125. 
Storer, T.I. 1919. The fly-catching habit among birds. Condor $21: 125$.

Swarth, H.S. 1904. Birds of the Huachuca Mountains, Arizona. Pacific Coast Avifauna 4. 70 p.

Swarth, H.S. 1924. Fall migration notes from the San Francisco Mountain region, Arizona. Condor $26: 183-190$.

Tatschl, J.L. 1967. Breeding birds of the Sandia Mountains and their ecological distributions. Condor $69: 479-490$.

Thomas, R.H. 1946. A study of Eastern Bluebirds in Arkansas. Wilson Bulletin 58:143-183.

Thomas, J.W. and D.C. McCluskey. 1974. Effects of aerial application of DDT for tussock moth control on nestling survival of Mountain Bluebirds and House Wrens. U.S.D.A. Forest Service Research Paper PNW-185. 37p.

Thompson, C.S. 1900. The woodpeckers of the upper Salinas Valley. Condor 2:52-55.

Thompson-Cowley, L.L., D.H. Helfer, G.D. Schmidt, and E.K. Eltzroth. 1979. Acanthocephalan parasitism in the Western Bluebird (Sialia mexicana). Avian Diseases $23: 768-771$.

Townsend, C.W. 1925. Winter birds seen at the Grand Canyon, Arizona. Condor 27:177-178.

Troetschler, R. 1976. Acorn Woodpecker breeding strategy as affected by Starling nest-hole competition. Condor $78: 151-165$.

U.S.D.A. Soil Conservation Service. 1974. General Soil Map. $130 \mathrm{p}$.

U.S. Environmental Data and Information Service. 1970-1981. Climatological Data: Oregon. National Oceanic and Atmospheric Administration, National Climatic Center, Asheville, North Carolina.

Walker, A. 1917. Some birds of central Oregon. Condor $19: 131-140$.

Wallace, G.J. 1959. The plight of the bluebird in Michigan. Wilson Bulletin 71:192-3. 
Walsberg, G.E. 1975. Digestive adaptations of Phainopepla nitens associated with the eating of mistletoe berries. Condor 77:169-174.

Walsberg, G.E. 1981. Nest-site selection and the radiative environment of the Warbling Vireo. Condor 83:86-88.

Watson, G.E. and A.B. Amerson, Jr. 1967. Instructions for collecting bird parasites. Smithsonian Institution, Museum of Natural History Information Leaflet 477 . $11 \mathrm{p}$.

Weld, L.G. 1932. Mortality among birds in Antelope Valley, California. Condor 34:137-138.

White, S.C. and G.E. Woolfenden. 1973. Breeding of the Eastern Bluebird in central Florida. Bird-Banding 44:110-123.

Willett, G. 1919. Bird notes from southeastern Oregon and northeastern California. Condor 21:194-207.

Williams, J.J. 1900. Probable causes of bird scarcity in parts of the Sierras, and arraignment of the chipmunk. Condor 2:97-101.

Winternitz, B.L. 1976. Temporal change and habitat preference of some montane breeding birds. Condor $78: 383-393$.

Zeleny, L. 1968. Bluebird nesting box temperatures. Atlantic Naturalist $23: 214-218$.

Zeleny, L. 1973. Help the bluebird. National Parks and Conservation 47:13-17.

Zeleny, L. 1976. The bluebird - How you can help its fight for survival. Indiana University Press, Bloomington. $170 \mathrm{p}$.

Zwickel, F.C. 1975. Nesting parameters of Blue Grouse and their relevance to populations. Condor 77:423-430. 